\title{
Effect of calcium on fatty acid bioaccessibility during in vitro digestion of Cheddar-type cheeses prepared with different milk fat fractions
}

\author{
Erik Ayala-Bribiesca, ${ }^{\dagger} \dagger$ Sylvie L. Turgeon, ${ }^{*}$ and Michel Britten $\dagger^{1}$ \\ *Institute of Nutrition and Functional Foods (INAF) and Dairy Science and Technology Research Centre (STELA), Laval University, Sainte-Foy, \\ Quebec, Canada, G1V OA6 \\ †Saint-Hyacinthe Research and Development Centre, Agriculture and Agri-Food Canada, 3600 Casavant Boulevard West, Saint-Hyacinthe, \\ Quebec, Canada, J2S 8E3
}

\begin{abstract}
Calcium plays an important role in intestinal lipid digestion by increasing the lipolysis rate, but also limits fatty acid bioaccessibility by producing insoluble $\mathrm{Ca}$ soaps with long-chain fatty acids at intestinal $\mathrm{pH}$ conditions. The aim of this study was to better understand the effect of $\mathrm{Ca}$ on the bioaccessibility of milk fat from Cheddar-type cheeses. Three anhydrous milk fats (AMF) with different fatty acid profiles (olein, stearin, or control AMF) were used to prepare Cheddar-type cheeses, which were then enriched or not with Ca using $\mathrm{CaCl}_{2}$ during the salting step. The cheeses were digested in vitro, and their disintegration and lipolysis rates were monitored during the process. At the end of digestion, lipids were extracted under neutral and acidic $\mathrm{pH}$ conditions to compare free fatty acids under intestinal conditions in relation to total fatty acids released during the digestion process. The cheeses prepared with the stearin (the AMF with the highest ratio of long-chain fatty acids) were more resistant to disintegration than the other cheeses, owing to the high melting temperature of that AMF. The Ca-enriched cheeses had faster lipolysis rates than the regular Ca cheeses. Chromatographic analysis of the digestion products showed that $\mathrm{Ca}$ interacted with long-chain fatty acids, producing $\mathrm{Ca}$ soaps, whereas no interaction with shorter fatty acids was detected. Although higher Ca levels resulted in faster lipolysis rates, driven by the depletion of reaction products as $\mathrm{Ca}$ soaps, such insoluble compounds are expected to reduce the bioavailability of fatty acids by hindering their absorption. These effects on lipid digestion and absorption are of interest for the design of food matrices for the controlled release of fat-soluble nutrients or bioactive molecules.
\end{abstract}

Key words: cheese structure, fat digestion, lipolysis, calcium soaps

Received August 22, 2016.

Accepted December 15, 2016.

${ }^{1}$ Corresponding author: michel.britten@agr.gc.ca

\section{INTRODUCTION}

Digestion is the process that allows the body to absorb nutrients from foods; however, not all ingested nutrients can be absorbed and used for normal body functions. Thus, the total amount of a nutrient in a food does not necessarily reflect the amount that can actually be absorbed. Nutrient bioaccessibility, which is the fraction of an ingested component that is released from the food matrix into the juices of the gastrointestinal tract, is an important factor influencing nutrient bioavailability (Watzke, 1998; Versantvoort et al., 2005).

The bioaccessibility of lipids depends greatly on the ability of the digestive system to free lipids from the food matrix and then transform them into an absorbable form. Triacylglycerols (TAG), which represent around $95 \%$ of dietary lipids, are hydrolyzed by digestive lipases to produce monoacylglycerols and fatty acids as end products (Carey et al., 1983; Jones and Kubow, 2006). Monoacylglycerols can be incorporated into mixed micelles for intestinal uptake in the jejunum and the ileum, whereas the absorption of fatty acids depends partly on the length of their carbon chain. Shortchain fatty acids (SCFA) and medium-chain fatty acids (MCFA) can be absorbed directly by the intestinal mucosa, whereas long-chain fatty acids (LCFA) must be assembled into mixed micelles to be transported for absorption (Bauer et al., 2005; Jones and Kubow, 2006; Guéguen and Pointillart, 2008). Furthermore, saturated LCFA may bind to Ca as insoluble soaps, significantly reducing their absorption rates (Guéguen and Pointillart, 2008; Astrup et al., 2010; Golding and Wooster, 2010). Nevertheless, the effect of $\mathrm{Ca}$ is not straightforward, because it may also increase fatty acid bioaccessibility by enhancing lipolysis (Hu et al., 2010).

Lipolysis takes place at the lipid/water interface between the fat droplets and the aqueous intestinal fluids. Once the lipids have been released from the food matrix, the next stage in lipid digestion is the formation of emulsified fat droplets, which creates a lipid/ 
water interface allowing the adsorption of lipase so that it can interact with the TAG in the fat droplet (Jones and Kubow, 2006). Adsorption of the enzyme to the interface causes a conformational rearrangement, exposing the catalytic site (Golding and Wooster, 2010). Lipolysis products are removed from the interphase by incorporation into mixed micelles with bile salts. However, as LCFA accumulate on such interface, they eventually limit the access of lipase to the remaining substrate (Favé et al., 2004; Bauer et al., 2005). At this stage of lipid digestion, Ca can play a major role in fatty acid bioaccessibility. Under $\mathrm{pH}$ conditions close to neutrality, such as those found in the jejunum and ileum, Ca reacts with saturated LCFA to form their corresponding Ca salts, commonly referred to as calcium soaps (CS; Owen et al., 1995). The removal of fatty acids from the fat droplet surface as CS allows lipase to access more substrate, increasing lipolysis rates (Patton and Carey, 1979; Hu et al., 2010). However, such CS form crystalline structures with extremely low water solubility (Harrison, 1924; Pereira et al., 2012), which disturbs their incorporation into mixed micelles and results in delayed fatty acid uptake.

Fat absorption from the lumen is generally quite efficient, with only about $4 \%$ of the ingested fat escaping into the feces (Carey et al., 1983). An increase in fat excretion when fat is taken in combination with high amounts of Ca has been shown in various studies, as reported in a recent meta-analysis, where dairy $\mathrm{Ca}$ intake of $1,241 \mathrm{mg} / \mathrm{d}$ resulted in an average increase in fecal fat of $5.2 \mathrm{~g} / \mathrm{d}$ (Christensen et al., 2009). In such studies, fat loss was related mainly to LCFA loss as CS.

Cheddar cheese is recognized as a good dietary source of Ca. From a technological point of view, Ca has a major role in structuring the protein matrix of Cheddar cheese (Lucey and Fox, 1993; Ong et al., 2013), and recent studies have shown that cheeses with different structures exhibit different breakdown patterns and lipolysis rates during in vitro digestion (Lamothe et al., 2012; Ayala-Bribiesca et al., 2016). The objective of our study was to determine the effect of $\mathrm{Ca}$ on the in vitro digestion and lipid bioaccessibility of Cheddartype cheeses prepared with different anhydrous milk fats (AMF). In practical terms, olein and stearin are AMF fractions whose melting points are lower and higher, respectively, than the melting point of a regular AMF. Olein fractions have a higher ratio of low-melting point TAG, which are generally rich in UFA and SCFA; stearin fractions are high in TAG with higher LCFA content (Lopez et al., 2006). The goal was to better understand how fat and $\mathrm{Ca}$ interact during cheese digestion and how such interactions may modify lipid bioaccessibility. Fat substitution in the model cheeses would be expected to result in different fatty acid-release profiles during lipolysis and, thus, different bioaccessibility profiles depending on the presence or absence of Ca. A better understanding of the role of $\mathrm{Ca}$ in the bioaccessibility of fatty acids in cheese will enable the development of technological strategies to manufacture functional food matrices. It would therefore be possible to harness lipid digestion to design tailored functional foods and optimize their nutritional value.

\section{MATERIALS AND METHODS}

\section{Characterization of AMF}

Three different AMF were used to prepare the creams for cheesemaking. The control AMF was prepared from commercial butter, which was melted at $80^{\circ} \mathrm{C}$, and the lipid phase was recovered by aspiration. Commercial olein and stearin AMF fractions (Anhydrous Milkfat Premium and Specialty Milkfat 42, respectively) were kindly provided by Fonterra Ltd. (Auckland, New Zealand).

Thermal analyses of AMF were performed by differential scanning calorimetry (DSC) using a Q2000 calorimeter (TA Instruments, Saint Quentin en Yvelines, France). The AMF samples were placed in $50-\mu \mathrm{L}$ aluminum pans and sealed hermetically. An empty pan was used as reference, and the equipment was calibrated with lauric acid (melting point $=43.7^{\circ} \mathrm{C}, \Delta \mathrm{H}_{\text {melting }}$ $=8.53 \mathrm{kcal} / \mathrm{mol}$ ). The samples were conditioned for 5 min at $70^{\circ} \mathrm{C}$ to melt all fat crystals and nuclei and then cooled to $-50^{\circ} \mathrm{C}$ at a rate of $1{ }^{\circ} \mathrm{C} / \mathrm{min}$, followed by heating to $70^{\circ} \mathrm{C}$ at a rate of $1^{\circ} \mathrm{C} / \mathrm{min}$. The final melting point of each fraction was determined from their thermograms, from the intersection of the baseline and the tangent to the last endothermic drop (Lopez et al., 2006).

Samples from each AMF type were methylated for fatty acid analysis (Luddy et al., 1968). All standards and reagents were obtained from Sigma Aldrich (St. Louis, MO). The solvents (HPLC-grade) were obtained from Fisher Scientific (Markham, ON, Canada). Heptanoic (C7:0) and nonadecanoic (C19:0) acids were added to the methylation tubes as internal standards to correct from 4- to 12-carbon fatty acids and from 14- to 18-carbon fatty acids, respectively. The AMF samples were treated with $0.4 \mathrm{~N}$ potassium methanolate in anhydrous methanol at $65^{\circ} \mathrm{C}$ for 2 min, mixed in a vortex mixer, and heated for another $30 \mathrm{~s}$. After the samples were cooled on ice, $300 \mu \mathrm{L}$ of $14 \% \mathrm{BF}_{3}$ in methanol was added, and the mixture was heated at $65^{\circ} \mathrm{C}$ for $2 \mathrm{~min}$, mixed in a vortex mixer, and cooled again on ice. This preparation sequence ensures the complete methylation 
of any free fatty acids present in the samples (Luddy et al., 1968). To extract the methyl esters, $0.6 \mathrm{~g}$ of $\mathrm{Na}_{2} \mathrm{SO}_{4}$ was added to each tube, followed by the addition of 5 $\mathrm{mL}$ of $n$-hexane, and the tubes were agitated in a vortex mixer for $1 \mathrm{~min}$. The methylation tubes were then centrifuged for 2 min at $3,000 \times g$ and the supernatant phase was analyzed.

Fatty acid profile analysis was performed by GC [6890A gas chromatograph with a flame-ionization detector (FID); Agilent Technologies, Mississauga, ON, Canada]. The inlet was a split-splitless type and kept at $250^{\circ} \mathrm{C}$ with a split ratio set to $25: 1$. Helium was used as carrier gas $(1.2 \mathrm{~mL} / \mathrm{min})$ and as make-up gas $(25$ $\mathrm{mL} / \mathrm{min})$. The column was fused silica and $30 \mathrm{~m} \times 0.25$ $\mathrm{mm}$ i.d. with a liquid phase of type DB-FFAP $\left[\mathrm{d}_{\mathrm{f}}(\right.$ film thickness $)=0.25 \mu \mathrm{m}$; J\&W; Chromatographic Specialties Inc., Brockville, ON, Canada]. After the automated injection, the oven temperature was kept at $50^{\circ} \mathrm{C}$ for $3 \mathrm{~min}$, increased at a rate of $15^{\circ} \mathrm{C} / \mathrm{min}$ to $200^{\circ} \mathrm{C}$, and kept at $200^{\circ} \mathrm{C}$ for $15 \mathrm{~min}$, for a total run time of $28 \mathrm{~min}$. Hydrogen $(35 \mathrm{~mL} / \mathrm{min})$ and compressed air $(350 \mathrm{~mL} /$ min) were used for the FID, which was kept at $300^{\circ} \mathrm{C}$. The molar percentage of each fatty acid was calculated with respect to the total fatty acids recovered.

The day before cheese production, each AMF was melted at $65^{\circ} \mathrm{C}$ in a double-wall vat. Raw skim milk (0.27\% fat; Laiterie Chalifoux, Sorel, QC, Canada) was added until a mass fraction of $36 \%$ fat mixture was obtained. The vat was mixed with a vane agitator, heated, and held at $65^{\circ} \mathrm{C}$ for $15 \mathrm{~min}$ before the mixture was pumped through the homogenizer (Two-phase, 200-L/h capacity, SN 185188; Rannie, Copenhagen, Denmark). The homogenizer was set to $2,500 \mathrm{kPa}$ (approximately $360 \mathrm{psi}$ ), because that was the equipment's lowest effective setting. After 2 passes through the homogenizer, the creams were rapidly cooled to $15^{\circ} \mathrm{C}$ and kept overnight at $4^{\circ} \mathrm{C}$.

Fat droplet size in the AMF creams was measured and compared with a native pasteurized cream by laser diffraction using a Mastersizer 2000 particle size analyzer (E ver. 5.54, SN MAL1023324; Malvern Instruments, Malvern, UK) equipped with a Hydro 2000MU sampler (Malvern Instruments). The cream samples were diluted at a 1:200 ratio in a dissociation buffer. The buffer was composed of $8 M$ urea, $50 \mathrm{mmol} / \mathrm{L}$ EDTA, and $10 \mathrm{mmol} / \mathrm{L}$ dithiothreitol, adjusted to $\mathrm{pH} 7$ with $1 \mathrm{~mol} / \mathrm{L} \mathrm{NaOH}$, and filtered at $0.45 \mu \mathrm{m}$ (Robin and Paquin, 1991). All chemicals were obtained from Sigma Aldrich. The buffer with sample was then added to distilled water directly in the sampler to an approximate 1:3,000 ratio, until an obscuration rate of $10 \%$ was obtained for the analysis. Specific surface area, surface-weighted median diameter, and volumeweighted median diameter were recorded.

\section{Cheddar-Type Cheeses}

Cheese Production. Cheeses were manufactured in the pilot plant at Agriculture and Agri-Food Canada's Saint-Hyacinthe Research and Development Centre (Saint-Hyacinthe, QC, Canada). Raw skim milk $(0.27 \%$ fat) purchased from a local company (Laiterie Chalifoux) was separated into 3 batches, which were standardized to a final fat mass fraction of $4.5 \pm 0.1 \%$ using the creams prepared with the different AMF. Each standardized milk was immediately pasteurized at $74.5^{\circ} \mathrm{C}$ for $18 \mathrm{~s}$ and then transferred into separate cheese vats (model 4-MX, 250 L, double-O type; Kusel Equipment, Watertown, WI) set to maintain the milk at $32^{\circ} \mathrm{C}$. The vats were filled with $225 \mathrm{~kg}$ of milk and $45 \mathrm{~mL}$ of a $450-\mathrm{g} / \mathrm{L} \mathrm{CaCl}_{2}$ solution (Cal-Sol $45 \%$; Fromagex, Rimouski, QC, Canada). The starter (FD-DVS Flora Danica, 100103; Chr. Hansen, Hørsholm, Denmark) was added directly into the vats at a rate of 50 $\mathrm{U} / 1,000 \mathrm{~L}$. When the milk reached $\mathrm{pH} 6.54 \pm 0.02$ and $14.5 \pm 0.5^{\circ} \mathrm{D}\left(1^{\circ} \mathrm{D}\right.$ is equivalent to $0.1 \mathrm{~g}$ of lactic acid per liter of milk), commercial microbial chymosin solution (ChyMax; Chr. Hansen) at $0.085 \mathrm{~mL} / \mathrm{kg}$, diluted in 30 volumes of distilled water, was added to each vat. Once set, the gels were cut and then cooked by increasing the temperature to $38^{\circ} \mathrm{C}$ at a rate of $0.2^{\circ} \mathrm{C} /$ min, after which the temperature was maintained. The whey was drained about $3 \mathrm{~h}$ after the gel was cut, when the $\mathrm{pH}$ of the whey was $6.06 \pm 0.04$. Cheddaring lasted about $2 \mathrm{~h}$, and the curds were milled when their $\mathrm{pH}$ reached $5.38 \pm 0.03$.

The milled curds from each vat were separated into 2 containers and salted with $\mathrm{NaCl}$ or a mixture of $\mathrm{NaCl}$ and $\mathrm{CaCl}_{2} \cdot 2 \mathrm{H}_{2} \mathrm{O}$ (Sigma-Aldrich), in which half of the $\mathrm{NaCl}$ was replaced with $\mathrm{CaCl}_{2} \cdot 2 \mathrm{H}_{2} \mathrm{O}$ in a $1: 1$ ionic-strength contribution ratio, as calculated with Equation 1:

$$
\mu=\frac{1}{2} \sum_{i} c_{i} Z_{i}^{2}
$$

where $\mu$ is the ionic strength of the solution, and $c_{i}$ and $Z_{i}$ are, respectively, the concentration and the charge of the ion $i$ (Barrow, 1979). The amounts of salts added to produce a regular- or a high-Ca cheese were, respectively, $2.42 \% \mathrm{NaCl}$ or $1.21 \% \mathrm{NaCl}+1.02 \%$ $\mathrm{CaCl}_{2} \cdot 2 \mathrm{H}_{2} \mathrm{O}$ (i.e., equivalent to the ionic strength of a $4.32 \% \mathrm{NaCl}$-in-moisture content in the milled curd, for both salting conditions). The salted curds were then packed into $13-\mathrm{kg}$ capacity stainless steel molds lined with synthetic cheesecloth and were pressed overnight at $275 \mathrm{kPa}$ (approximately $40 \mathrm{psi}$ ) at room temperature. When removed from the molds, the cheeses were vacuum-packed and kept at $4^{\circ} \mathrm{C}$ for $84 \mathrm{~d}$, after which 
they were cut into smaller blocks that were individually vacuum-packed. The individually wrapped blocks were kept at $4^{\circ} \mathrm{C}$ until required for the experiments, which were completed within $21 \mathrm{~d}$.

Cheese Composition and Mineral Profile. All reagents for composition analyses were obtained from Fisher Scientific. Moisture was quantified by difference from TS, obtained by oven-drying at $100^{\circ} \mathrm{C}$ for $16 \mathrm{~h}$. The solids were then ashed at $550^{\circ} \mathrm{C}$ for $16 \mathrm{~h}$. Protein was quantified by the Kjeldahl method using 6.38 as the nitrogen-to-protein factor. Fat was quantified by Mojonnier ether extraction. Cheese $\mathrm{pH}$ was measured in a slurry prepared from $10 \mathrm{~g}$ of cheese and $10 \mathrm{~g}$ of distilled water.

Main cations (i.e., $\mathrm{Ca}, \mathrm{Na}, \mathrm{K}$, and $\mathrm{Mg}$ ) and $\mathrm{P}$ were quantified by inductively coupled plasma-optical emission spectroscopy from the cheese ashes. The ashes were dissolved in $0.23 \mathrm{~mol} / \mathrm{L}$ of $\mathrm{HNO}_{3}$, centrifuged for $15 \mathrm{~min}$ at $3,000 \times g$ at $22^{\circ} \mathrm{C}$, and filtered through a $0.45-\mu \mathrm{m}$ polyethersulfone filter. Commercial standards (Fisher Scientific) were diluted in the same acidic matrix and filtered. An ICP spectrometer (Prism 010-00084-1; Teledyne Leeman Labs, Hudson, NH) was equipped with a Peek Mira Mist Nebulizer (PMM4000; Burgener Research, Mississauga, ON, Canada). The emission lines used for element quantification for $\mathrm{Ca}, \mathrm{Na}, \mathrm{K}$, $\mathrm{Mg}$, and $\mathrm{P}$ were $317.933,589.592,766.490,279.080$, and $213.618 \mathrm{~nm}$, respectively. Detection was performed in radial mode on the argon-plasma torch.

Cheese Structure. The microstructure of the experimental cheeses was observed by scanning electron microscopy and confocal laser scanning microscopy imaging. Hardness was measured by axial compression of cheese cylinders.

Cheese samples were prepared as reported in a previous study (Ayala-Bribiesca et al., 2016), and scanning electron micrographs of typical fields were recorded using an XL30 environmental scanning electron microscope (Philips, Eindhoven, the Netherlands). For confocal laser scanning microscopy, thick slices (approximately $0.5 \mathrm{~mm}$ ) of fresh cheese at $4^{\circ} \mathrm{C}$ were cut with a razor blade and mounted in a hybridization well affixed on a microscope slide to stabilize the coverslip over the thick slice of cheese. Fat and protein in the samples were simultaneously stained over ice with a $0.01 \%$ aqueous solution of Nile Blue A (Sigma-Aldrich). After $2 \mathrm{~min}$, the excess liquid was removed, and the sample was covered with Fluoromount-G (Southern Biotechnology Associates Inc., Birmingham, AL) and a coverslip and observed under a Zeiss 510 Meta confocal laser scanning microscope equipped with a Zeiss $40 \times /$ NA 1.4 Plan Apochromat objective lens (Carl Zeiss $\mathrm{GmbH}$, Jena, Germany). Fat was detected at $488 \mathrm{~nm}$ of excitation of an Argon/2 laser and with a 530- to 600$\mathrm{nm}$ band-pass emission filter, and protein was detected at $633 \mathrm{~nm}$ of excitation of an HeNe laser and with a 650-nm long-pass emission filter. The slides were kept over a refrigerated surface during observation to reduce fat mobility and coalescence. The images were processed with Zen software (v.2009, Carl Zeiss GmbH), with green and red pseudocolors assigned to fat and protein, respectively.

Cheese hardness was obtained from the peak force of a compression cycle (Bourne, 1978) using a TA-XT2 texture analyzer (Stable Micro Systems, Surrey, UK) and according to the parameters used in a previous study (Ayala-Bribiesca et al., 2016). Cylindrical samples (radius $=5 \mathrm{~mm}$; height $=10 \mathrm{~mm}$ ) were equilibrated for 30 min at $22^{\circ} \mathrm{C}$ for the temperature at which the cheese would enter the mouth or at $37^{\circ} \mathrm{C}$ for the temperature of digestion, and the samples were then compressed to a $30 \%$ strain with a probe moving at $0.4 \mathrm{~mm} / \mathrm{s}$.

\section{In Vitro Digestion}

The in vitro digestion was based on a static gastrointestinal model for the fed state simulating oral, gastric, and small intestine digestion and was carried out in $50-\mathrm{mL}$ tubes with head-over-heels agitation (Versantvoort et al., 2005), with the modifications presented in a previous study (Ayala-Bribiesca et al., 2016). The tubes contained $3.0 \mathrm{~g}$ of cheese cut into 3 -mm cubes and $2.5 \mathrm{~g}$ of glass beads, in agreement with considerations explained elsewhere (Ayala-Bribiesca et al., 2016). Oral, gastric, and intestinal fluids were sequentially added at 0,5 , and $120 \mathrm{~min}$, respectively. The total duration of digestion was $270 \mathrm{~min}$, and the system was maintained at $37^{\circ} \mathrm{C}$ throughout the process. A new digestion tube was sampled for analysis at each time point (i.e., after 5, 60, 120, 135, $150,180,240$, and $270 \mathrm{~min})$. The in vitro digestions were performed in triplicate.

Matrix Disintegration Index. Physical disintegration of the cheeses was quantified using the matrix degradation index (MDI), obtained from the amount of cheese solids dispersed in the digestion fluids, as previously described (Lamothe et al., 2012). Briefly, large cheese particles were separated using a metallic sieve with 1.5-mm mesh. The drained liquid was used for fatty acid and CS analyses. The retained solids were washed twice with $5 \mathrm{~mL}$ of unused digestive fluids at $37^{\circ} \mathrm{C}$ (saliva, gastric, or intestinal fluid, depending on the time point of sampling). The cheese solids were then transferred to a tinfoil dish, dried, and weighed. The mass of dry solids was used to obtain the MDI, using Equation 2: 


$$
\operatorname{MDI}(\%)=100 \times \frac{C S_{0}-C S_{t}}{C S_{0}},
$$

where $C S_{0}$ is the mass of cheese solids originally present in the digestion tube, and $C S_{t}$ is the mass of cheese solids remaining at time $t$. Physical disintegration of the matrix was quantified after 5, 60, 120, 135, 150, 180, 240, and $270 \mathrm{~min}$.

Lipolysis Kinetics. The extent of lipolysis during in vitro digestion was measured using a fatty acid enzymatic colorimetric kit (Roche Diagnostics, Indianapolis, IN). The chyme samples were handled and prepared as previously described (Ayala-Bribiesca et al., 2016). Absorbance was measured at $546 \mathrm{~nm}$ with a DU 800 spectrophotometer (Beckman Coulter, Fullerton, CA) equipped with a tungsten lamp. Oleic acid was used as the calibration standard. Samples were analyzed after $120,135,150,180,240$, and $270 \mathrm{~min}$ of in vitro digestion. Given that pancreatic lipase cleaves only $s n_{1^{-}}$and $s n_{3}$-fatty acids from the triglyceride molecule (Jones and Kubow, 2006), theoretically only $2 / 3$ of the TAG fatty acids could be released. Lipolysis was expressed as the mass fraction (\%) of fatty acids released from the AMF present in the cheese sample, assuming an average molecular weight of $247 \mathrm{~g} / \mathrm{mol}$ for milk fatty acids (Lamothe et al., 2012). In parallel, the $\mathrm{pH}$ of the liquid fraction of the chyme was recorded at $60,120,135,150$, 180, 240, and $270 \mathrm{~min}$.

Fatty Acid Bioaccessibility. At the end of digestion (270 min), aliquots of the chyme juice (approximately $1 \mathrm{~mL}$ ) were transferred into two 50-mL Teflon highspeed centrifuge tubes (05-562-16B, Cat. \# 3114-0050; Fisher Scientific, Ottawa, ON, Canada). The masses of chyme juice added were recorded, and $10 \mathrm{~mL}$ with distilled water and $80 \mu \mathrm{L}$ of $5 \mathrm{~N} \mathrm{H}_{2} \mathrm{SO}_{4}$ were added to the tubes. Preliminary tests (not shown) confirmed that the $\mathrm{pH}$ of the tube contents was always less than or equal to 2.0. Such acidic conditions dissociate any CS and protonate fatty acids, enabling their transfer into the organic phase (de Jong and Badings, 1990). The lipids were extracted by adding $10 \mathrm{~mL}$ of ethanol and $10 \mathrm{~mL}$ of a 1:1 volumetric mixture of diethyl ether and hexane. Once the solvents had been added, the tubes were tightly closed, mixed with a vortex mixer, and transferred into an orbital shaker, where they were mixed in the horizontal position at $150 \mathrm{rpm}$ for $5 \mathrm{~min}$ in a chamber at $37^{\circ} \mathrm{C}$. The tubes were then centrifuged at room temperature for $3 \mathrm{~min}$ at $3,000 \times g$ (Sorvall ST-40R centrifuge, TX-750 rotor, 3608 round bucket; Thermo Fisher Scientific, Waltham, MA). The supernatant organic phase was removed with a Pasteur pipette and placed in $40-\mathrm{mL}$ amber glass vials containing
$2 \mathrm{~g}$ of $\mathrm{Na}_{2} \mathrm{SO}_{4}$. Two more extractions with $10 \mathrm{~mL}$ of $1: 1$ diethyl ether and hexane followed. The extracts were pooled in the vials, and tridecanoic acid (C13:0) was added as an internal standard. The fatty acids were separated by solid-phase extraction using commercially available aminopropyl cartridges $\left(\mathrm{NH}_{2}\right.$ Sep-Pak Plus, WAT020535; Waters, Taunton, MA) that were first conditioned with a $10-\mathrm{mL}$ wash of $n$-hexane. After the conditioning step, the contents of each vial were emptied into the solid-phase extraction cartridge funnels. The eluted solvent was recovered, used to rinse the vials, and eluted once again. Nonpolar lipids were removed from the solid-phase extraction cartridges by eluting $10 \mathrm{~mL}$ of a 2:1 chloroform-isopropanol mixture. The fatty acids were desorbed with $4 \mathrm{~mL}$ of $2 \%$ formic acid in diethyl ether solution. All elutions were performed at a rate of $2 \mathrm{~mL} / \mathrm{min}$. The fatty acids in the solutions were quantified by GLC (6890A gas chromatograph equipped with an FID; Agilent Technologies). The inlet was a split type and kept at $250^{\circ} \mathrm{C}$ with a split ratio set to 10:1. Hydrogen was used as carrier gas $(9 \mathrm{~mL} /$ min), and nitrogen was used as make-up gas $(25 \mathrm{~mL} /$ $\mathrm{min})$. The column was fused silica and $15 \mathrm{~m} \times 0.53 \mathrm{~mm}$ i.d. with a liquid phase of type DB-FFAP $\left(d_{\mathrm{f}}=1 \mu \mathrm{m}\right.$; J125-3212; Agilent Technologies). After the automatic injection, the oven temperature was kept at $115^{\circ} \mathrm{C}$ for 3 min, increased at a rate of $10^{\circ} \mathrm{C} / \mathrm{min}$ to $240^{\circ} \mathrm{C}$, and kept at $240^{\circ} \mathrm{C}$ for $15 \mathrm{~min}$, for a total run time of $30.5 \mathrm{~min}$. The FID was kept at $300^{\circ} \mathrm{C}$. Individual fatty acids were identified and calibrated with their respective commercial standards (Sigma Aldrich). Overall bioaccessibility, as related to the extent of lipolysis, refers to the sum of individual fatty acids in relation to total fatty acids originally present (as TAG) in the AMF, and the bioaccessibility profile refers to the mass fraction (\%) of each fatty acid released after in vitro digestion and recovered in the acidic extraction in relation to the same fatty acid originally present (as TAG) in the AMF used to prepare the experimental cheese.

Calcium Enrichment and Fatty Acid Solubility. To evaluate the effect of Ca enrichment on the precipitation of individual fatty acids, an extraction of chyme juice was performed at $\mathrm{pH} 7$, which represents conditions that can be normally found in the small intestine (Diem and Lentner, 1970). Chyme juice collected at the end of in vitro digestion was adjusted to $\mathrm{pH} 7.00 \pm$ 0.02 with a $5 \mathrm{~mol} / \mathrm{L}$ solution of $\mathrm{NaOH}$. Less than 150 $\mu \mathrm{L}$ of base per $10 \mathrm{~mL}$ of chyme juice was required to obtain the target $\mathrm{pH}$, and thus the dilution effect was negligible. The samples were submitted to the same extraction as detailed for fatty acid bioaccessibility, except that no acid was added to the extraction tube. Loss ratios for each fatty acid between the extraction 
pairs were compared among the different AMF types and the different $\mathrm{Ca}$ levels of the experimental cheeses using Equation 3, as follows:

$$
L R=1-\frac{F A_{7}}{F A_{2}},
$$

where, for chymes obtained after the digestion of each experimental cheese, $L R$ is the loss ratio for each fatty acid between the extraction pairs, $F A_{2}$ is the amount of the fatty acid quantified in the organic phase of the extraction performed at $\mathrm{pH} 2$, and $F A_{7}$ is the amount of the fatty acid quantified in the organic phase of the extraction performed at $\mathrm{pH} 7$.

Last, the effect of the Ca enrichment of the Cheddartype cheeses on CS formation was estimated by gravimetrically comparing the extraction rate differences between the high-Ca cheeses prepared with each AMF type and their respective regular-Ca counterparts. To that end, a second series of extractions at $\mathrm{pH} 2$ and 7 was performed on chyme juice collected at the end of digestion. To extract gravimetrically quantifiable masses of lipids, the chyme juice samples were increased to approximately $10 \mathrm{~mL}$. Once the sample was weighed, extractions proceeded as detailed for the fatty acid analyses, except that no water was added and that, for the acidic extractions, $600 \mu \mathrm{L}$ of $2.5 \mathrm{M} \mathrm{H}_{2} \mathrm{SO}_{4}$ was required to reach $\mathrm{pH} 2$. The organic phases of 3 extractions were pooled in a pre-weighed tinfoil dish. The solvents were left to evaporate for $12 \mathrm{~h}$ at room temperature under a fume hood and the cups were then weighed. The mass fraction of fat lost between each extraction pair was computed by subtracting the mass fraction of fat extracted from the chyme juice at $\mathrm{pH}$ 7 from that obtained through the extraction at $\mathrm{pH} 2$ (Equation 4); the increment in CS due to Ca enrichment $\left(\Delta_{\mathrm{CS}}\right)$ was defined as the mass loss between the high and low Ca levels of cheeses prepared with each AMF type (Equation 5):

$$
\begin{gathered}
\mathrm{ML}=\mathrm{m}_{2}-\mathrm{m}_{7}, \\
\Delta_{\mathrm{CS}}=\mathrm{ML}_{\text {highCa }}-\mathrm{ML}_{\text {regularCa }},
\end{gathered}
$$

where ML is the mass fraction of fat lost between the extraction pairs, for each AMF and Ca level; $\mathrm{m}_{2}$ is the mass fraction of fat extracted at $\mathrm{pH} 2 ; \mathrm{m}_{7}$ is the mass fraction of fat extracted at $\mathrm{pH} 7 ; \Delta_{\mathrm{CS}}$ is the increment of fat loss as CS due to Ca enrichment of cheeses with each AMF; $\mathrm{ML}_{\mathrm{highCa}}$ is the mean of the mass fraction of fat lost for high Ca levels for each AMF; and $\mathrm{ML}_{\text {regularCa }}$ is the mean of the mass fraction of fat lost for regular Ca levels for each AMF.

\section{Statistical Analysis}

Results for AMF thermal analysis and cream characterization were analyzed using a 1-way ANOVA, and comparisons were performed using the least square difference with a significance threshold of $P \leq 0.05$. Cheese physicochemical analyses were performed on triplicate samples, unless otherwise specified. The data were analyzed for statistical differences by a 2-way ANOVA in a split-plot array with the AMF type nested in the main plot and the salting condition in the subplot. Multiple comparisons were performed using the least square difference with a significance threshold of $P \leq$ 0.05 . The in vitro digestion results and cheese hardness data were analyzed for statistical differences using a 3-way ANOVA in a split-plot array with the AMF type and salting condition in the main plot and the digestion time or the compression temperature for digestion or hardness, respectively, nested in the subplot. Multiple comparisons were performed using the least squares difference with a significance threshold of $P \leq$ 0.05. The fatty acid composition of the bioaccessible lipid fraction was analyzed using a 2-way ANOVA in a completely random design for the AMF and Ca level. The least squares difference was used for the multiple comparisons with a significance threshold of $P \leq 0.05$. All statistical analyses were performed with SAS 9.3 TS Level 1M0 software (SAS Institute, Cary, NC).

\section{RESULTS AND DISCUSSION}

\section{Creams for Cheesemaking}

$\boldsymbol{A} \boldsymbol{M F}$. Thermograms obtained by DSC (Figure 1) revealed similar thermal behavior between the control and olein AMF, whereas the behavior of the stearin fraction was distinct. The control AMF presented the typical aspect of a milk fat thermogram (Lopez et al., 2006). Olein and stearin AMF thermal behavior may vary according to the specific conditions of the milk fat fractionation progress (Kaylegian and Lindsay, 1995). Crystallization events (Figure 1a) started at different temperatures $(P<0.0001)$ for all AMF types (Table 1), with the highest temperature for the stearin AMF and the lowest for the olein AMF. Final melting points (Table 1) determined from the last endothermic event (Figure 1b) also differed for all $\operatorname{AMF}(P<$ 0.0001). The olein AMF final melting point was slightly lower (by approximately $1^{\circ} \mathrm{C}$ ) than that of the control $\operatorname{AMF}\left(35.43^{\circ} \mathrm{C}\right)$, whereas the stearin AMF final melting point was considerably higher (by approximately $7^{\circ} \mathrm{C}$ ), in agreement with their crystallization behavior. Although the small exothermic peak of control AMF at $16^{\circ} \mathrm{C}$ (Figure 1a) would explain the slight shift in 


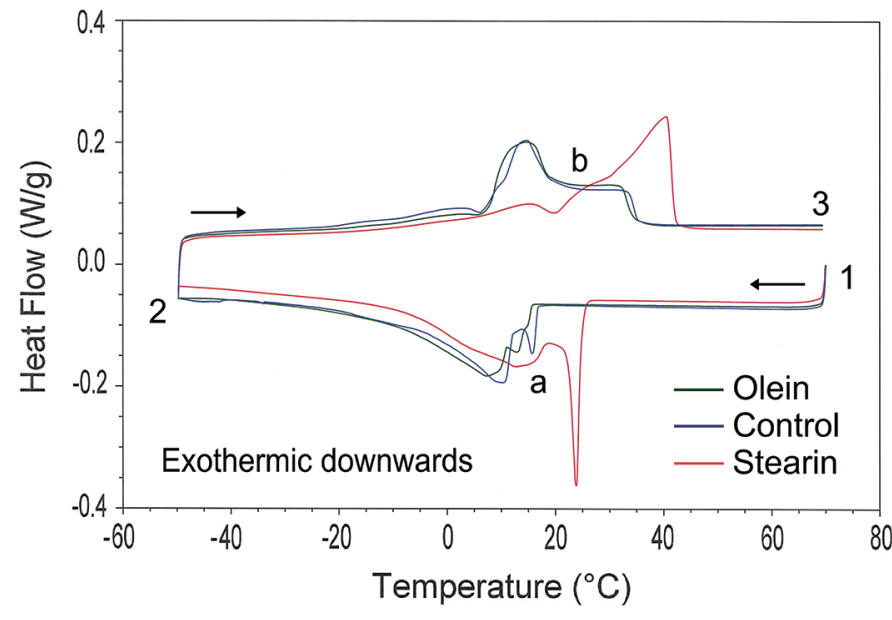

Figure 1. Differential scanning calorimetry thermograms of the control, olein, and stearin anhydrous milk fats recorded during a crystallization and melting cycle from 70 to $-50^{\circ} \mathrm{C}$ ( 1 to 2 ) and -50 to $70^{\circ} \mathrm{C}(2$ to 3$)$ at a rate of $1^{\circ} \mathrm{C} / \mathrm{min}$. Exothermic (a) and endothermic (b) events are shown for the crystallization and melting spans, respectively. Color version available online.

the melting profile for the olein AMF, for all practical purposes both the olein and control AMF are expected to be completely molten during the in vitro digestion process.

The fatty acid profiles of the AMF are presented in Table 2. Differences in individual fatty acid reflected the nature of the olein and stearin fractions, although the olein was closer in composition to the control than the stearin was. This closeness would explain the similar behavior during the DSC analysis, where only small shifts in the melting and crystallizations events were observed between the olein and the control, whereas greater differences were observed for the stearin in comparison with the control. The main differences among the AMF were (a) increased SCFA and MCFA in the olein, (b) an unexpectedly higher amount of UFA in the control, possibly explained by the different origins of the AMF, and (c) increased LCFA in the stearin, replacing mainly UFA and SCFA, in comparison with the other AMF. The specific composition of fractionated AMF varies according to the crystallization intervals

Table 1. Main thermal events obtained from differential scanning calorimetry thermograms recorded at $1^{\circ} \mathrm{C} / \mathrm{min}$ for olein, control, and stearin anhydrous milk fats (AMF)

\begin{tabular}{lcc}
\hline AMF & $\begin{array}{c}\text { Crystallization } \\
\text { start }\left({ }^{\circ} \mathrm{C}\right)\end{array}$ & $\begin{array}{c}\text { Final melting } \\
\text { point }\left({ }^{\circ} \mathrm{C}\right)\end{array}$ \\
\hline Olein & $15.60^{\mathrm{c}}$ & $34.70^{\mathrm{c}}$ \\
Control & $16.81^{\mathrm{b}}$ & $35.43^{\mathrm{b}}$ \\
Stearin & $25.31^{\mathrm{a}}$ & $42.32^{\mathrm{a}}$ \\
SEM & 0.02 & 0.03 \\
\hline
\end{tabular}

${ }^{\mathrm{a}-\mathrm{c}}$ Different letters denote different means within a column.
Table 2. Fatty acid composition of the olein, control, and stearin anhydrous milk fats (AMF)

\begin{tabular}{lrrrr}
\hline & \multicolumn{2}{c}{ Fatty acids in AMF $($ molar \%) } & \\
\cline { 2 - 3 } Fatty & \multicolumn{1}{c}{ Olein } & Control & Stearin & \multirow{2}{*}{ SEM } \\
\hline acid & $10.88^{\mathrm{a}}$ & $10.15^{\mathrm{a}}$ & $6.94^{\mathrm{b}}$ & 0.31 \\
C4:0 & $5.66^{\mathrm{a}}$ & $4.98^{\mathrm{b}}$ & $3.31^{\mathrm{c}}$ & 0.08 \\
C6:0 & $2.69^{\mathrm{a}}$ & $2.28^{\mathrm{b}}$ & $1.52^{\mathrm{c}}$ & 0.03 \\
C8:0 & $5.34^{\mathrm{a}}$ & $4.37^{\mathrm{b}}$ & $3.29^{\mathrm{c}}$ & 0.06 \\
C10:0 & $6.63^{\mathrm{b}}$ & $4.41^{\mathrm{c}}$ & $7.15^{\mathrm{a}}$ & 0.09 \\
C12:0 & $13.41^{\mathrm{b}}$ & $11.76^{\mathrm{c}}$ & $14.41^{\mathrm{a}}$ & 0.04 \\
C14:0 & $1.19^{\mathrm{b}}$ & $1.02^{\mathrm{c}}$ & $1.49^{\mathrm{a}}$ & $<0.01$ \\
C15:0 & $28.25^{\mathrm{c}}$ & $30.67^{\mathrm{b}}$ & $35.17^{\mathrm{a}}$ & 0.10 \\
C16:0 & $0.52^{\mathrm{c}}$ & $0.53^{\mathrm{b}}$ & $0.72^{\mathrm{a}}$ & $<0.01$ \\
C17:0 & $10.34^{\mathrm{b}}$ & $10.14^{\mathrm{c}}$ & $13.22^{\mathrm{a}}$ & 0.06 \\
C18:0 & $13.70^{\mathrm{b}}$ & $17.70^{\mathrm{a}}$ & $12.21^{\mathrm{c}}$ & 0.05 \\
C18:1 & $0.85^{\mathrm{b}}$ & $1.70^{\mathrm{a}}$ & $0.57^{\mathrm{c}}$ & 0.11 \\
C18:2 & $0.54^{\mathrm{a}}$ & $0.27^{\mathrm{ab}}$ & $0.00^{\mathrm{b}}$ & 0.08 \\
C18:3 & & 0.200 & \\
\hline
\end{tabular}

${ }^{a-c}$ Different letters denote different means within a row.

used during manufacture (deMan and Finoro, 1980; Kaylegian and Lindsay, 1995), which suggests that the olein fraction was depleted only of some high-melting point TAG. Nevertheless, the overall variation between the olein and stearin AMF was consistent with what was expected (deMan and Finoro, 1980; Kaylegian and Lindsay, 1995).

Preparation of Creams. The dispersion of the AMF in skim milk yielded creams with similar specific surface areas, surface-weighted median diameters, and volume-weighted median diameters (Table 3). In all cases, the fat droplets in AMF creams were smaller than those present in a cream containing native fat globules $(P<0.001$; Table 3$)$. These results confirm the resemblance of the standardization creams with respect to their fat droplet size. No changes in the median values were observed from the preparation of the creams to their incorporation into the milk for the cheesemaking process (results not shown).

\section{Cheddar-Type Cheeses}

Cheese Composition and Mineral Profile. In all cases, the experimental cheeses had a composition within the expected ranges for a regular full-fat Cheddar cheese (Health Canada, 2010; Minister of Justice of Canada, 2014), although their compositions differed slightly (Table 4). Differences among the cheeses were found for moisture (AMF type, $P=0.0062$ ), protein (AMF type, $P=0.0036$ ), fat (AMF type, $P=0.0371$; Ca level, $P=0.0416$ ), ash (AMF type $\times$ Ca level, $P=$ 0.0049 ), and $\mathrm{pH}$ (AMF type $\times$ Ca level, $P=0.0017)$.

The cheeses prepared with the olein AMF had a slightly higher moisture and protein contents than the cheeses prepared with the other AMF. Nevertheless, the moisture-to-protein ratio of the cheeses was be- 
Table 3. Characterization by laser diffraction of fat droplets in a native cream (included as a reference) and in anhydrous milk fat (AMF)-creams obtained by mild homogenization of olein, control, and stearin AMF in skim milk ${ }^{1}$

\begin{tabular}{lccc}
\hline AMF in cream & $\begin{array}{c}\text { Specific surface } \\
\text { area }\left(\mathrm{m}^{2} / \mathrm{g}\right)\end{array}$ & $\begin{array}{c}\text { Surface-weighted } \\
\text { diameter }\left(\mathrm{d}_{(3,2)} \text { in } \mu \mathrm{m}\right)\end{array}$ & $\begin{array}{c}\text { Volume-weighted } \\
\text { diameter }\left(\mathrm{d}_{(4,3)} \text { in } \mu \mathrm{m}\right)\end{array}$ \\
\hline Native & $2.18^{\mathrm{b}}$ & $2.76^{\mathrm{a}}$ & $3.77^{\mathrm{a}}$ \\
Olein & $2.83^{\mathrm{a}}$ & $2.13^{\mathrm{b}}$ & $2.51^{\mathrm{b}}$ \\
Control & $2.81^{\mathrm{a}}$ & $2.14^{\mathrm{b}}$ & $2.59^{\mathrm{b}}$ \\
Stearin & $2.81^{\mathrm{a}}$ & $2.13^{\mathrm{b}}$ & $2.72^{\mathrm{b}}$ \\
SEM & 0.06 & 0.05 & 0.12 \\
\hline
\end{tabular}

${ }^{\mathrm{a}, \mathrm{b}}$ Different superscript letters denote significant differences within means reported for each analysis.

${ }^{1}$ Median values are reported for surface- and volume-weighed diameters.

tween 1.51 and 1.58 , suggesting similar protein hydration levels. In a previous study, Cheddar cheeses were salted by adding $\mathrm{CaCl}_{2}$ instead of replacing $\mathrm{NaCl}$ on an ionic-strength basis, and the result was major variation in moisture-to-protein ratios (i.e., from 1.24 to 1.62; Ayala-Bribiesca et al., 2016). Incorporating $\mathrm{CaCl}_{2}$ by replacing $\mathrm{NaCl}$ was successful in obtaining cheeses with limited moisture-to-protein variations.

In compensation for their higher protein and moisture contents, the olein AMF cheeses had the lowest fat content, although the variations were small and were significant only in relation to the cheeses prepared with the stearin AMF with the high Ca level. Ash was more abundant in the cheeses with the regular $\mathrm{Ca}$ level in comparison with the high-Ca cheeses, although that difference was not significant for the cheeses prepared with the stearin AMF. Differences between the highand regular-Ca conditions were due to the different masses of salt added, given that a lower mass of $\mathrm{CaCl}_{2}$ than of $\mathrm{NaCl}$ is required to obtain an equivalent ionic strength. Finally, the cheeses with $\mathrm{CaCl}_{2}$ added during salting had lower $\mathrm{pH}$ values than those salted only with $\mathrm{NaCl}$. As expected, this difference was due to the reaction of the $\mathrm{Ca}$ with phosphate and citrate, freeing $\mathrm{H}^{+}$ into the aqueous phase (Philippe et al., 2003).

Salting conditions modified the mineral profiles of the experimental cheeses (Table 5$)$ in terms of their Ca $(P$ $=0.0002), \mathrm{K}(P=0.0172)$, and $\mathrm{Na}(P<0.0001)$ concentrations. No significant differences were detected for
$\mathrm{Mg}$ or P. The AMF types did not influence the mineral composition of the experimental cheeses. The Ca concentration in the regular-Ca cheeses was similar to the value $(7,210 \mu \mathrm{g} / \mathrm{g})$ reported for commercial Cheddar cheese (Health Canada, 2010). The Ca concentration in the high-Ca cheeses increased $33 \%$ (by $2,330 \mu \mathrm{g} / \mathrm{g}$ in comparison with the regular-Ca cheeses) when $\mathrm{CaCl}_{2}$ was added during the salting step. As expected, the $\mathrm{Na}$ concentration decreased in the high-Ca cheeses in comparison with the regular-Ca cheeses due to the lower amount of $\mathrm{Na}$ added during the salting step. Higher $\mathrm{K}$ losses after the salting step were observed in the highCa cheeses in comparison with the regular-Ca cheeses. These losses occurred after the salts were added and during the pressing step. Potassium is present mainly as free ions, so it is more diffusible during the osmotic drainage of cheese than are $\mathrm{Mg}$ and $\mathrm{P}$, which are partly bound to proteins in colloidal associations (Gaucheron, 2005).

Cheese Structure. The scanning electron microscopy images revealed similar cheese microstructures for all the experimental cheeses. The cheeses presented similar features (Figure 2), with a continuous protein matrix embedded with small and abundant fat globules. The size of the fat droplets shown in the scanning electron microscopy images are in accordance with the results reported for fat droplet size (Table 3). The finer fat dispersion is explained by the mild homogenization performed to disperse the AMF, which is in contrast

Table 4. Composition, as mass fraction, and $\mathrm{pH}$ of experimental cheeses prepared with different anhydrous milk fats (AMF) and salted with $\mathrm{NaCl}$ (regular Ca level) or $\mathrm{NaCl}+\mathrm{CaCl}_{2}$ (high Ca level)

\begin{tabular}{llccccc}
\hline AMF & Ca level & Moisture $\%$ & Protein $\%$ & Fat $\%$ & Ash $\%$ & $\mathrm{pH}$ \\
\hline Olein & Regular & $35.5^{\mathrm{ab}}$ & $23.5^{\mathrm{ab}}$ & $33.1^{\mathrm{c}}$ & $3.60^{\mathrm{a}}$ & $5.45^{\mathrm{a}}$ \\
& High & $35.8^{\mathrm{a}}$ & $23.7^{\mathrm{a}}$ & $32.6^{\mathrm{c}}$ & $3.45^{\mathrm{b}}$ & $5.17^{\mathrm{c}}$ \\
Control & Regular & $34.9^{\mathrm{abc}}$ & $22.1^{\mathrm{c}}$ & $33.7^{\mathrm{bc}}$ & $3.61^{\mathrm{a}}$ & $5.44^{\mathrm{a}}$ \\
& High & $34.1^{\mathrm{c}}$ & $22.5^{\mathrm{bc}}$ & $35.3^{\mathrm{bc}}$ & $3.30^{\mathrm{c}}$ & $5.19^{\mathrm{c}}$ \\
\multirow{2}{*}{ Stearin } & Regular & $34.9^{\mathrm{abc}}$ & $22.0^{\mathrm{c}}$ & $33.7^{\mathrm{bc}}$ & $3.51^{\mathrm{ab}}$ & $5.43^{\mathrm{a}}$ \\
\multirow{2}{*}{ SEM } & High & $34.4^{\mathrm{bc}}$ & $22.3^{\mathrm{c}}$ & $35.9^{\mathrm{b}}$ & $3.48^{\mathrm{ab}}$ & $5.25^{\mathrm{b}}$ \\
\hline
\end{tabular}

${ }^{\mathrm{a}-\mathrm{c}}$ Different superscript letters denote significant differences within means reported for each analysis. 

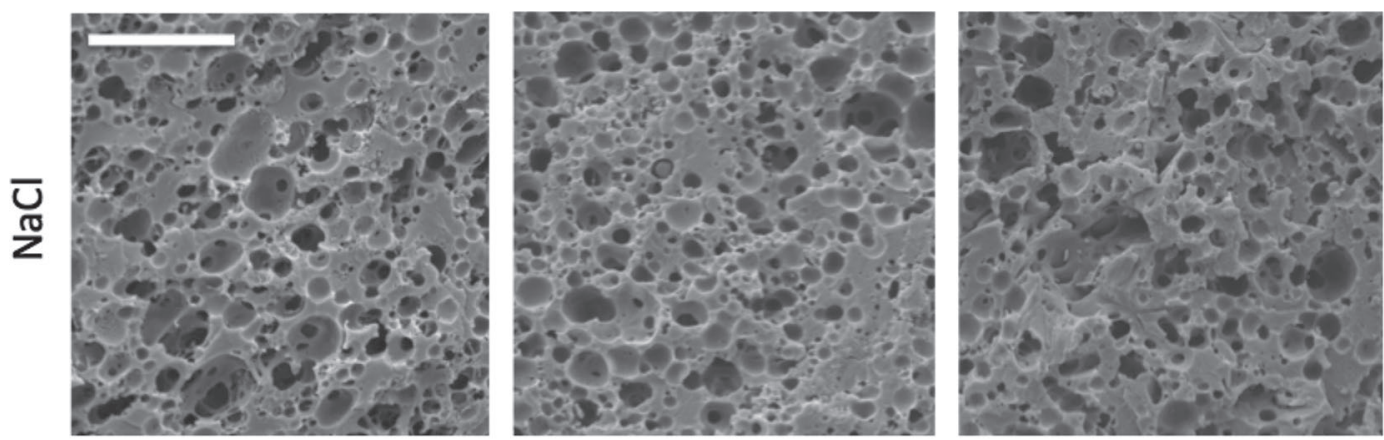

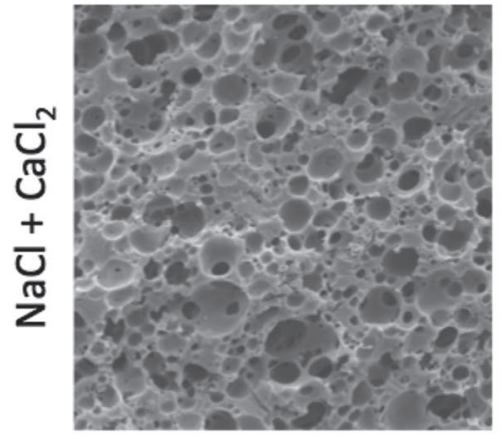

Olein

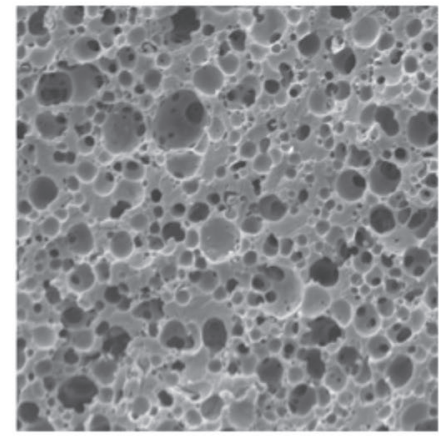

Control

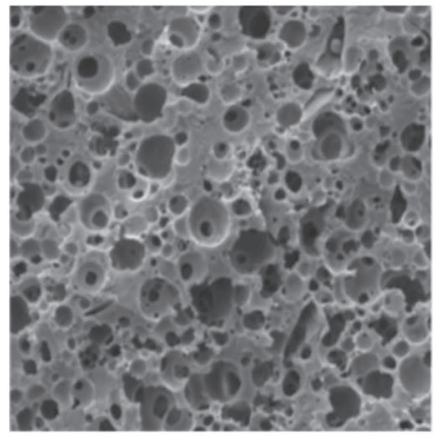

Stearin

Figure 2. Scanning electron micrographs of Cheddar-type cheeses prepared with olein, control, or stearin anhydrous milk fats and with regular or high $\mathrm{Ca}$ levels for salting conditions with $\mathrm{NaCl}$ or $\mathrm{NaCl}+\mathrm{CaCl}_{2}$, respectively. Voids represent the space once occupied by fat. Bar $=10 \mu \mathrm{m}$

to commercial or regular Cheddar cheeses, where the fat is present as native milk fat globules. Furthermore, the distribution of the fat globules within the protein matrix was homogeneous and coalescence was limited, as confirmed by the numerous individual fat droplets depicted in the confocal laser scanning microscopy images (Figure 3).

Cheese hardness varied according to the analysis temperature and the AMF type $(P=0.0013)$ used for the cheese preparation (Figure 4 ), but no effect was detected for the different $\mathrm{Ca}$ levels. At $22^{\circ} \mathrm{C}$, the cheeses prepared with the stearin AMF were more than $50 \%$ harder $(P<0.0001)$ than those prepared with the olein and control AMF. This behavior is explained by the different melting profiles of the different AMF types (Figure 1b); the olein and control fractions have a large endothermic event before $20^{\circ} \mathrm{C}$, indicating that an important part of their fat was liquid at the analysis temperature of $22^{\circ} \mathrm{C}$. In contrast, the major endothermic event of the stearin fraction begins at $20^{\circ} \mathrm{C}$; therefore, most of its fat is still solid at $22^{\circ} \mathrm{C}$. Analysis of hardness at $37^{\circ} \mathrm{C}$ did not reveal any significant differences among the cheeses, although the cheese samples with the stearin AMF retained their shape better than the other cheeses. Indeed, the DSC thermograms (Figure 1b) show that the olein and control AMF were molten at $37^{\circ} \mathrm{C}$, whereas the stearin $\mathrm{AMF}$ still had some solid fat at that temperature.

Table 5. Major minerals in experimental regular-Ca cheeses (salted with $\mathrm{NaCl}$ ) and high-Ca cheeses (salted with $\mathrm{NaCl}+\mathrm{CaCl}_{2}$; all anhydrous milk fat sources combined), as determined by inductively coupled plasmaoptical emission spectroscopy

\begin{tabular}{lccccc}
\hline & \multicolumn{5}{c}{ Major minerals $(\mu \mathrm{g} / \mathrm{g})$} \\
\cline { 2 - 5 } $\begin{array}{l}\text { Salting } \\
\text { conditions }\end{array}$ & $\mathrm{Ca}$ & $\mathrm{K}$ & $\mathrm{Mg}$ & $\mathrm{Na}$ & $\mathrm{P}$ \\
\hline $\mathrm{NaCl}$ & 7,136 & 387 & 280 & 5,867 & 3,863 \\
$\mathrm{NaCl}+\mathrm{CaCl}_{2}$ & $9,466^{* * *}$ & $277^{*}$ & $273^{\mathrm{NS}}$ & $2,881^{* * *}$ & $4,303^{\mathrm{NS}}$ \\
$\mathrm{SEM}$ & 68 & 16 & 3 & 39 & 218 \\
\hline
\end{tabular}

${ }^{*} P<0.05,{ }^{* * *} P<0.001$. 

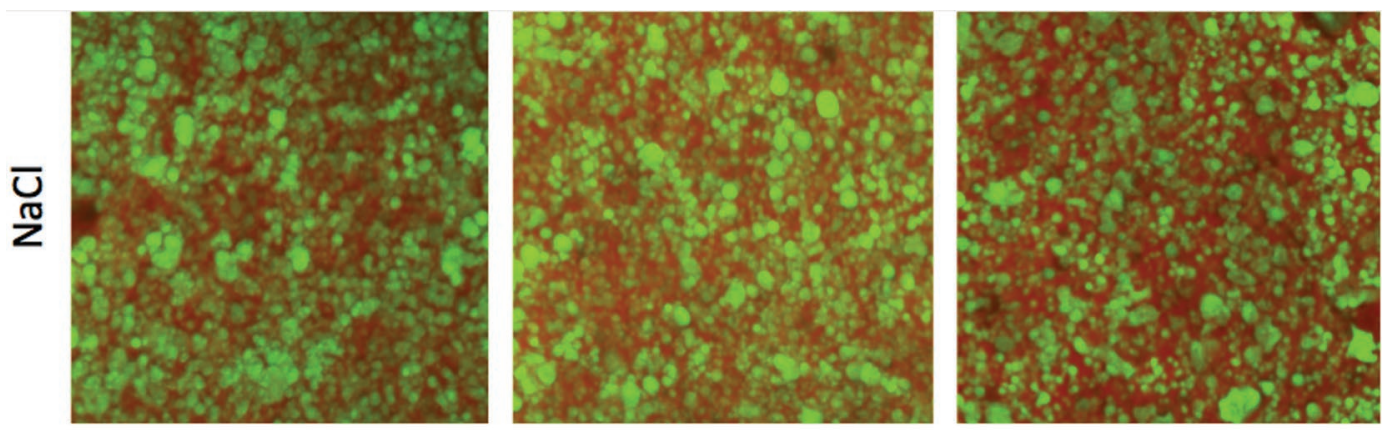

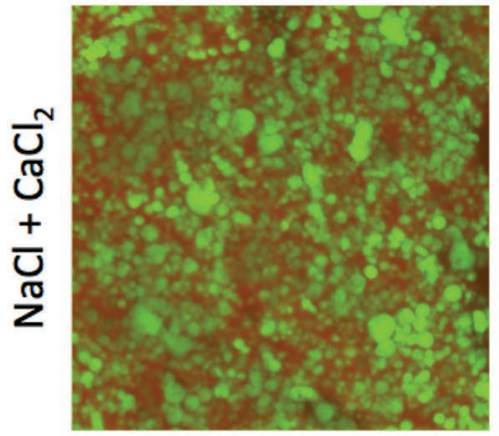

Olein

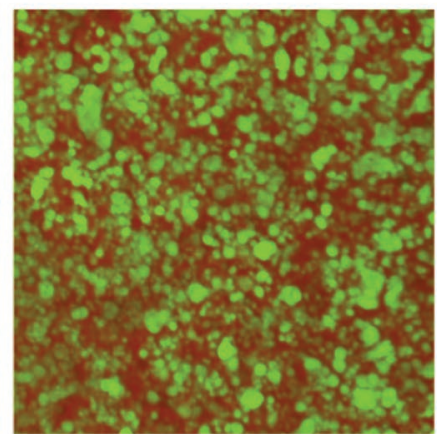

Control

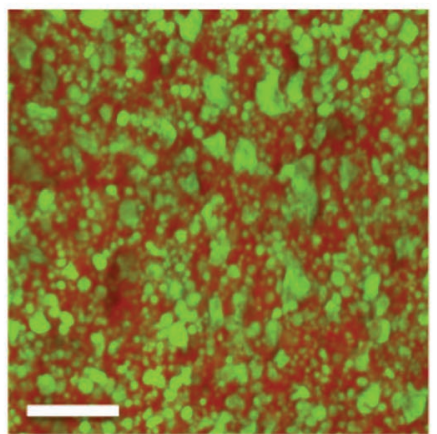

Stearin

Figure 3. Confocal laser scanning microscopy images of Cheddar-type cheeses prepared with olein, control, or stearin anhydrous milk fats and with regular or high $\mathrm{Ca}$ levels for salting conditions with $\mathrm{NaCl}$ or $\mathrm{NaCl}+\mathrm{CaCl}_{2}$, respectively. Green and red channels represent fat and protein, respectively. Overlapping channels show the distribution of fat within the protein matrix. Bar $=20 \mu \mathrm{m}$.

\section{In Vitro Digestion}

Matrix Disintegration Index. During in vitro digestion, the MDI varied over time differently for the AMF types $(P<0.0001)$, whereas no effect was detected for the different Ca levels. The MDI after the oral and gastric phases was consistently lower $(P<$ 0.0001) for the cheeses prepared with the stearin AMF than for the cheeses prepared with the other AMF types (Figure 5). With respect to the cheeses recovered in the mesh, those prepared with the stearin preserved their shape for longer during digestion (results not shown). Although no statistical difference was found for cheese hardness at $37^{\circ} \mathrm{C}$, the DSC results indicate that part of the stearin AMF would be solid at the digestion temperature, a fact that could explain the greater resistance to disintegration of those cheeses. As the intestinal phase progressed, the gap separating the MDI of the cheeses prepared with the stearin AMF from the MDI of the other cheeses quickly decreased, and the pancreatic enzymes helped complete the disintegration of all matrices within $1 \mathrm{~h}$ of the start of intestinal digestion (Figure 5). As previously suggested (Ayala-Bribiesca et al., 2016), the cheese matrix swells with fluid during gastric digestion; thus, pancreatic proteases can act more quickly when the intestinal fluids are added. The cheeses prepared with the olein and control AMF behaved the same way throughout digestion. The DSC results show that the thermal properties of the olein and control AMF were similar

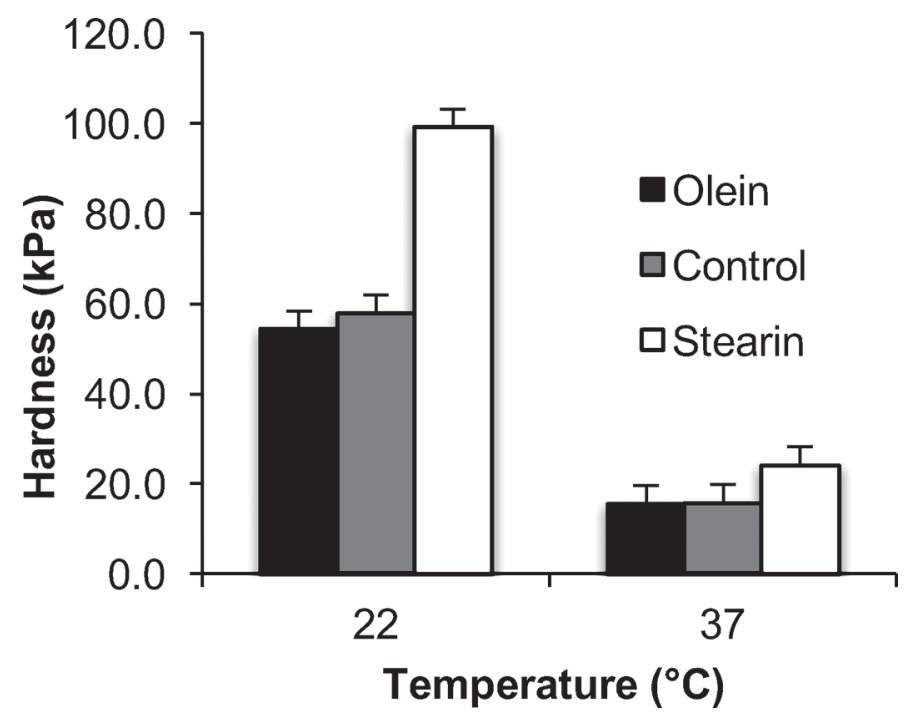

Figure 4. Hardness of Cheddar-type cheeses prepared with olein, control, or stearin anhydrous milk fats. Analyses were performed on cheese cylinders stabilized at 22 and $37^{\circ} \mathrm{C}$. Bars indicate $\mathrm{SEM}=0.32$. 
compared with those of the stearin AMF, further suggesting that AMF was the main factor involved in the different disintegration profiles, especially given that the overall composition and structure of the cheeses did not differ greatly. The results obtained for MDI agree with those previously obtained using the same in vitro system for Cheddar-type cheeses, where the matrixes underwent only partial disintegration during the gastric phase and quickly accelerated their disintegration as the intestinal fluids were added (Lamothe et al., 2012; Ayala-Bribiesca et al., 2016).

Lipolysis Kinetics. Lipolysis during in vitro digestion of the Cheddar-type cheeses was affected by time, AMF type, and $\mathrm{Ca}$ level in a statistically significant triple interaction $(P<0.0001)$. Lipolysis during the oral and gastric phases was considered negligible, given that no lipases were added in the simulated fluids for those phases. Small amounts of fatty acids (in statistically equivalent amounts for all the cheeses) were detected before the addition of the simulated intestinal fluids. Although lipolysis is low in young Cheddar cheeses made from pasteurized milk (Collins et al., 2004; Hickey et al., 2007), the presence of fatty acids in the experimental cheeses can be explained by the occurrence of some lipolysis during the dispersion of the AMF in raw milk before the mild homogenization treatment. The lipases naturally present in raw milk (Deeth and Fitz-Gerald, 1995; O'Mahony et al., 2013) entered in contact with the exposed AMF droplets (i.e., those with no protective milk fat globule membrane), allowing the enzymes to access the TAG (Favé et al., 2004; Armand, 2008) before being denatured by pasteurization (Keenan and Patton, 1995).

As expected, lipolysis increased sharply after the intestinal fluids were added (Figure 6). After $15 \mathrm{~min}$ of intestinal digestion, lipolysis was slower for the cheeses prepared with the stearin AMF, regardless of the Ca level, than for the other cheeses $(P \leq 0.0006)$. In contrast, the cheeses with the olein $\mathrm{AMF}$ and the high Ca level had the highest extent of lipolysis during the first $30 \mathrm{~min}$ of intestinal digestion $(P<0.0001)$. The faster lipolysis rates observed for the olein and control AMF during the first hour of intestinal digestion appear to be due to the higher SCFA and MCFA contents in those AMF in comparison with the stearin AMF. When present, SCFA are almost completely positioned in the $\mathrm{sn}_{1}$ and $\mathrm{sn}_{3}$ positions of the TAG (Christie, 1995; Michalski, 2008), where they are accessible to cleavage by pancreatic lipase, which is specific to those positions (Armand, 2008). Furthermore, SCFA and MCFA are relatively water-soluble under intestinal $\mathrm{pH}$ conditions (Bugaut, 1987; Marten et al., 2006), so they are less prone to accumulate at the lipid/water interface (Armand, 2008); lipase can thus access its substrate more

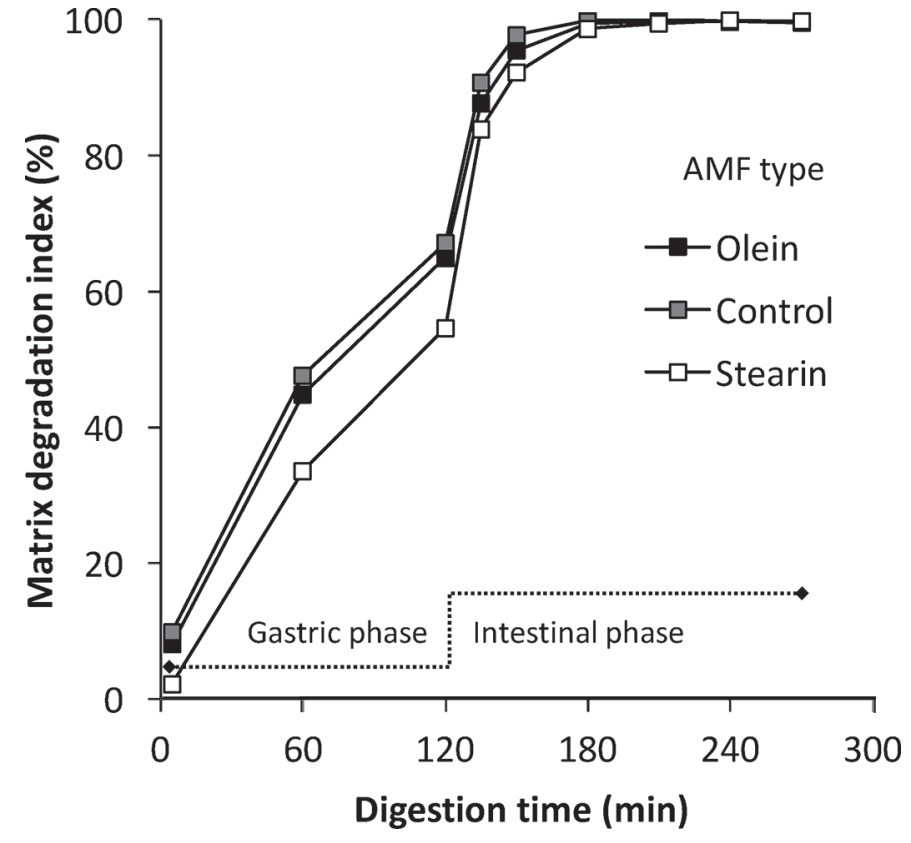

Figure 5. Matrix degradation index of Cheddar-type cheeses prepared with olein, control, or stearin anhydrous milk fats (AMF) during in vitro digestion. $\mathrm{SEM}=0.9$.

easily, in addition to the fact that TAG containing such fatty acid partition preferentially onto the fat droplet surface (Favé et al., 2004). Likewise, MCFA are released by pancreatic lipase faster than LCFA (Mu and Porsgaard, 2005). In sum, the higher amount of shorter fatty acids (which are more easily cleaved by lipases and have higher water solubility in comparison with longer fatty acids) appeared to have allowed lipolysis to be higher for the control and olein AMF than for the stearin AMF. The control AMF contained considerably more oleic acid (C18:1) and less MCFA than the olein AMF did; these differences could explain the lower lipolysis at the beginning of the intestinal phase. Oleic acid is present mainly in the $\mathrm{sn}_{1}$ and $\mathrm{sn}_{3}$ positions of milk fat (Christie, 1995), which were more abundantly occupied by SCFA and MCFA in the olein AMF. The fact that oleic acid is not water-soluble, in contrast to SCFA and MCFA, would explain the delayed lipolysis of the control AMF in comparison with the olein AMF. The faster lipolysis of the control AMF in comparison with that of the stearin AMF appears to be due to the physical state of the fat. Lipolysis of solid fat has been shown to be slower than that of liquid fat (Berry et al., 2007; Bonnaire et al., 2008), because the digestive lipases have less access to solid fat (Michalski et al., 2013).

The cheeses with the stearin AMF had considerably more LCFA, which are more prone to remain in the fat droplet because of their longer aliphatic moiety 

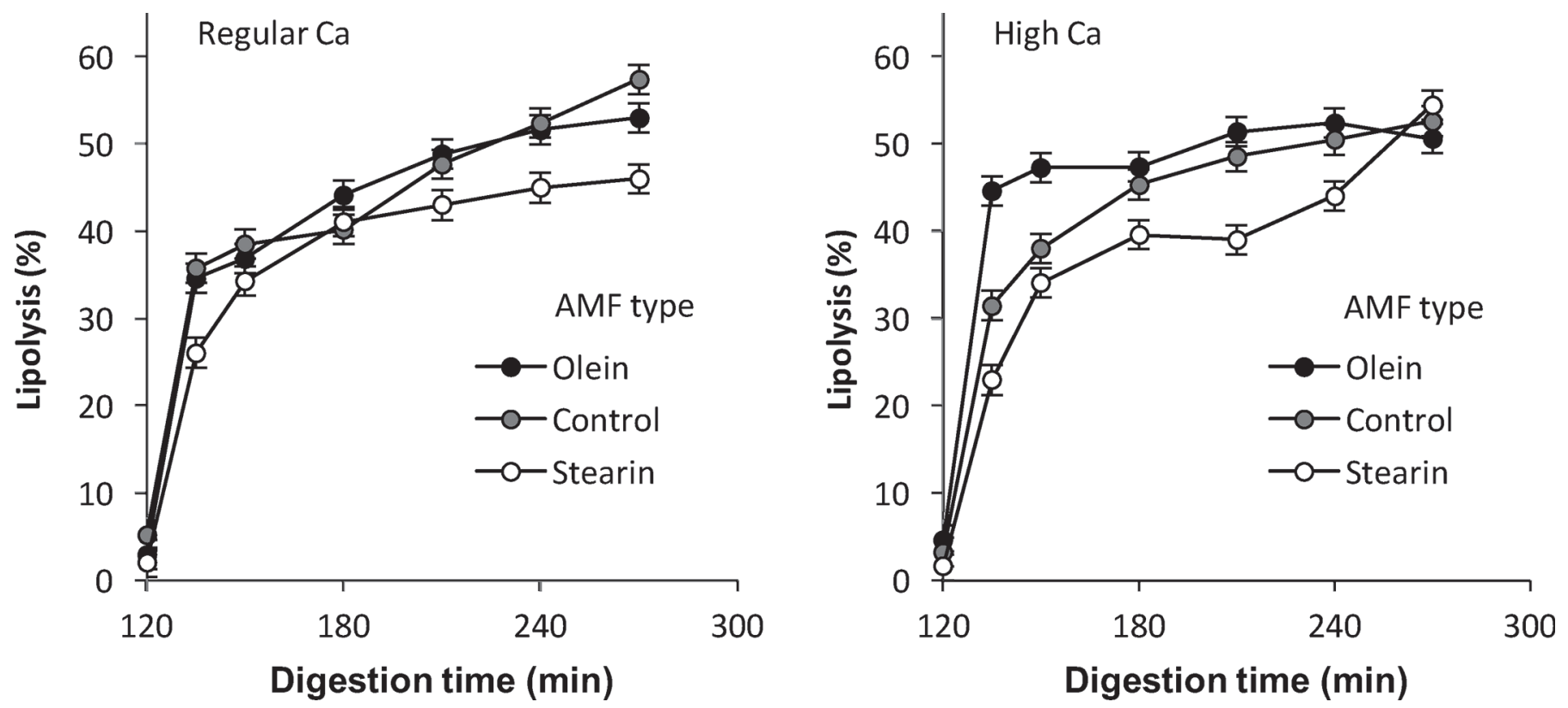

Figure 6. Progression of lipolysis [\% as the mass fraction of nonesterified fatty acids in relation to the anhydrous milk fat (AMF)] during the intestinal phase of the in vitro digestion of Cheddar-type cheeses prepared with olein, control, or stearin AMF and with regular or high Ca levels for cheeses salted with $\mathrm{NaCl}$ or $\mathrm{NaCl}+\mathrm{CaCl}_{2}$, respectively. Bars indicate SEM.

and lower water affinity. Toward the end of digestion, lipolysis of the stearin AMF increased considerably for the cheeses with a high $\mathrm{Ca}$ level and the stearin AMF $(P=0.0007)$ in comparison with the regular-Ca cheeses with the same AMF. This clearly shows the effect that Ca has on fatty acid release by depleting LCFA from the lipid/water interface and, thus, allowing further lipolysis (Patton and Carey, 1979; Sassene et al., 2014). At the end of digestion, the final lipolysis rates were similar for all conditions (Figure 6) except the cheeses with the stearin AMF and the regular Ca level $(P \leq$ 0.007), which had the only final rate under $50 \%$.

During the in vitro digestions, the $\mathrm{pH}$ varied over time differently for the AMF types $(P<0.0001)$. Although the $\mathrm{pH}$ of chyme (Figure 7 ) was influenced mainly by the intrinsic conditions provided by the digestion fluids, the cheeses prepared with olein caused a slightly higher buffering effect $(P=0.008)$ toward the end of gastric digestion than the other cheeses because of their overall faster disintegration. During the intestinal phase, the $\mathrm{pH}$ of the chyme from the cheeses prepared with the stearin AMF was higher than the $\mathrm{pH}$ of the other cheeses $(P<0.003$; Figure 7$)$, possibly owing to slower lipolysis, which provided less $\mathrm{H}^{+}$as free fatty acids were released ( $\mathrm{Li}$ et al., 2011). Lastly, the effect of the salting conditions $(P=0.0015)$ on the $\mathrm{pH}$ of chyme was that the cheeses with the high Ca level had a lower $\mathrm{pH}$, with an overall difference of $0.07 \mathrm{pH}$ units (data not shown). That difference could be explained by the lipolysis-enhancing effect of $\mathrm{Ca}$ (Hu et al., 2010).
Fatty Acid Bioaccessibility. The overall bioaccessibility of fatty acids varied according to the AMF type and the Ca level of the experimental cheeses $(P=$

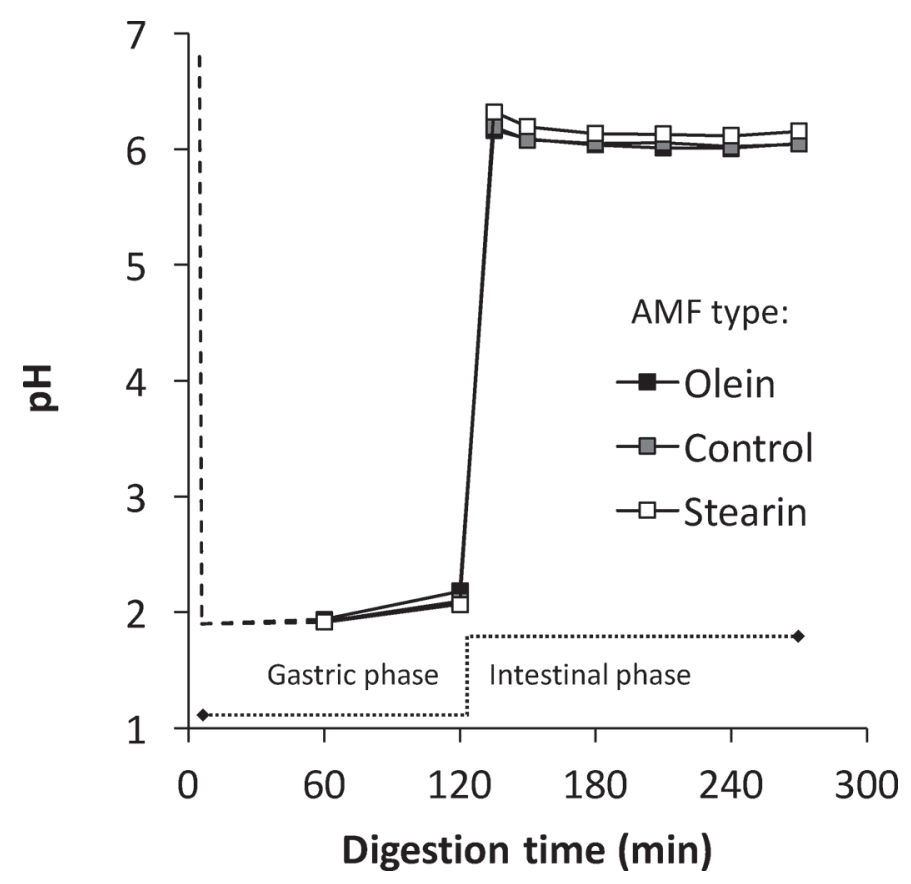

Figure 7. Change in $\mathrm{pH}$ during the in vitro digestion of Cheddartype cheeses prepared with olein, control, or stearin anhydrous milk fats (AMF). The dotted line indicates the expected $\mathrm{pH}$ before the first sample was taken after 60 min of gastric digestion. $\mathrm{SEM}=0.02$. 
0.0096). When regular Ca levels were present, the olein and control AMF had equivalent overall bioaccessibility, whereas the stearin AMF had a lower value (Table 6 ). The overall bioaccessibility values were in agreement with the final lipolysis rates obtained at the end of the in vitro digestion of the respective cheeses (Figure 6; regular $\mathrm{Ca}$ ). The $\mathrm{Ca}$ enrichment of the cheeses had different effects on overall bioaccessibility depending on the AMF present. As expected, the high Ca level in the cheeses prepared with the stearin AMF enhanced lipolysis and, thus, induced an increase in overall bioaccessibility. This would be explained by the removal of fatty acids from the surface of fat droplets (as CS) so that lipase could access its substrate. High $\mathrm{Ca}$ had no effect on the cheeses with the olein AMF, possibly because of their higher content of SCFA, which can easily be released into the aqueous phase of the chyme. Surprisingly, the Ca enrichment of cheeses with the control AMF slightly reduced their overall bioaccessibility in comparison with their regular-Ca counterparts. Nevertheless, the overall fatty acid bioaccessibility of all the cheeses with the high Ca level was equivalent, and the values are in agreement with the results obtained for the final lipolysis rates (Figure 6; high Ca).

When overall bioaccessibility is broken down for the individual fatty acids, AMF type had an effect on LCFA bioaccessibility $(P \leq 0.0002$; Figure 8$)$, and an AMF type $\times$ Ca level interaction was found for the bioaccessibility of SCFA $(P \leq 0.0314)$, MCFA $(P \leq$ $0.0096)$, and oleic acid $(P=0.0002$; Figure 9$)$. The Ca level did not appear to have a significant effect on LCFA bioaccessibility, a somewhat surprising result given that higher release rates of LCFA were expected in the presence of $\mathrm{Ca}$. One possibility is that the available $\mathrm{Ca}$ in the chyme was depleted as LCFA soaps, and then the Ca-induced lipolytic enhancement of the stearin $\mathrm{AMF}$ was reflected in the higher release rates of SCFA, MCFA, and oleic acid in comparison with the regular Ca level (Figure 9). No significant effect for Ca level was observed for any fatty acid of the other AMF types. It should be remembered that bioaccessibility was defined as the amount of individual fatty acids released during in vitro digestion (or the sum of the amounts of all the fatty acids, when referring to overall bioaccessibility); that amount is related to the extent of lipolysis and therefore does not account for fatty acid residues that are absorbable as $\mathrm{sn}_{2}$-monoacylglycerols or for the loss of bioaccessibility due to the formation of CS. For these reasons, the exact amount of bioaccessible fatty acids is uncertain because the acidic conditions during fat extraction dissociated the CS formed during the in vitro digestion of the cheeses.

The main difference in the overall behavior of the stearin AMF, with respect to the other AMF types,
Table 6. Overall bioaccessibility of fatty acids after in vitro digestion of experimental cheeses prepared with different anhydrous milk fat $(\mathrm{AMF})$ types (defined as the $\%$ of fatty acid released from triacylglycerols during digestion in relation to the total amount of fatty acid present in the respective $\mathrm{AMF}$ )

\begin{tabular}{llc}
\hline AMF & Ca level & $\begin{array}{c}\text { Overall } \\
\text { bioaccessibility } \%\end{array}$ \\
\hline Olein & Regular & $56.8^{\mathrm{a}}$ \\
Control & High & $55.7^{\mathrm{ab}}$ \\
\multirow{2}{*}{ Stearin } & Regular & $57.5^{\mathrm{a}}$ \\
\multirow{2}{*}{ SEM } & High & $55.5^{\mathrm{b}}$ \\
& Regular & $48.6^{\mathrm{c}}$ \\
\hline
\end{tabular}

${ }^{\mathrm{a}-\mathrm{c}}$ Different letters indicate significant differences.

was most likely related to the physical state of the fat, given that the stearin AMF had solid portions of fat at $37^{\circ} \mathrm{C}$; this slowed down the lipolysis process overall (Lopez et al., 2013), as observed for the progression of lipolysis during in vitro digestion. The stearin AMF was also the richest in LCFA in comparison with the other AMF; thus, the Ca that was present formed soaps, which enabled enzyme access to other fatty acids, as reflected by significant increases in SCFA, MCFA, and oleic acid (Figure 9). Although the results do not show a significant effect of $\mathrm{Ca}$ level on the bioaccessibility of individual LCFA, the overall effect was significant.

Differences in fatty acid bioaccessibility among the AMF could also be related to oleic acid (C18:1) and its role during digestion. Oleic acid is the second most abundant fatty acid in milk fat (after palmitic acid, C16:0) and is almost completely esterified in the $\mathrm{sn}_{1}$ and $\mathrm{sn}_{3}$ positions (Jensen and Newburg, 1995; Kaylegian and Lindsay, 1995; Michalski, 2008). The fact that high lipolysis rates were reached during the in vitro digestions suggests that most of the oleic acid was released. Oleic acid is highly hydrophobic, so it cannot leave the lipid/water interface spontaneously, as SCFA can, and would depend on bile salts to be removed from the interface. Therefore, as the system became saturated with reaction products, oleic acid would probably accumulate at the interface, given that oleic acid is less prone to precipitate with $\mathrm{Ca}$ in comparison with saturated LCFA, such as myristic (C14:0), palmitic (C16:0), and stearic (C18:0) acid (Björklund Jansson and Wadsborn, 2005; Garrett, 2013).

Further discussion of these results would require information on fatty acid stereospecificity within the TAG structures of the different AMF. The fatty acid composition and structure of AMF may fluctuate, especially for olein and stearin fractions, as they can vary considerably depending on the fractionation methods used (deMan and Finoro, 1980; Kaylegian and Lindsay, 1995; Lopez et al., 2006). 


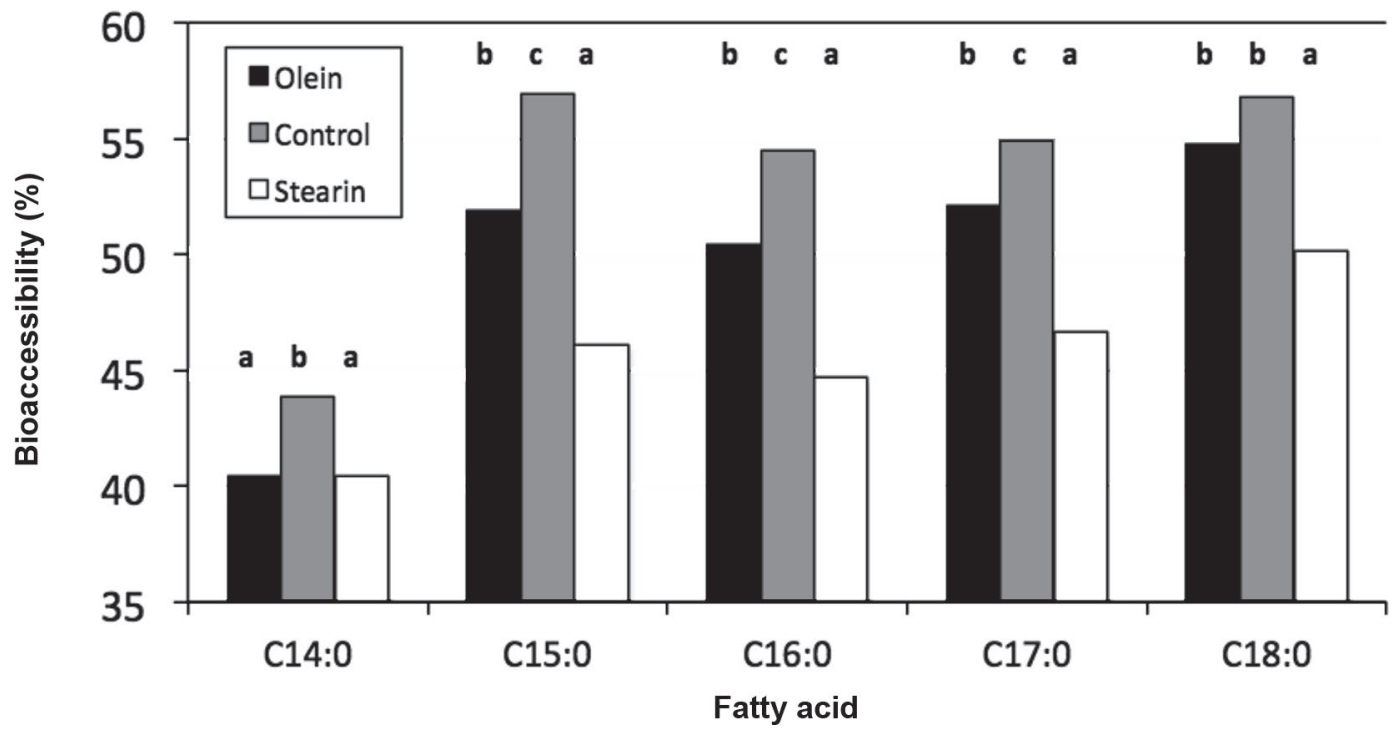

Figure 8. Bioaccessibility of saturated long-chain fatty acids after the in vitro digestion of Cheddar-type cheeses prepared with different anhydrous milk fat types [defined as the mass fraction (\%) of fatty acids released from triacylglycerols during digestion in relation to the total amount of the corresponding fatty acid present in the respective anhydrous milk fats]. Different letters (a-c) indicate significant differences within bar groups; SEM $\leq 0.7$ for all fatty acids.

Calcium Enrichment and Fatty Acid Solubility. Neither the AMF types nor the Ca level caused any differences in the loss ratios between each extraction pair for any fatty acid. As previously mentioned, the lipids lost during extractions at $\mathrm{pH} 7$ include not only fatty acids bound as CS but also dissociated water-soluble fatty acids, whose water solubility increases as the chain length decreases. The GC analysis failed to detect any fatty acids from $\mathrm{C} 4: 0$ to $\mathrm{C} 8: 0$ in the extracts obtained from chymes adjusted at $\mathrm{pH} 7$, indicating that none of those fatty acids partitioned to the organic phase at that $\mathrm{pH}$ (Table 7). At the same time, partitioning into the supernatant organic phase increased proportionally with the chain length for the other SFA (Table 7).

These results show that the proportion of fatty acids that are soluble at $\mathrm{pH} 7$ does not depend on their rela-

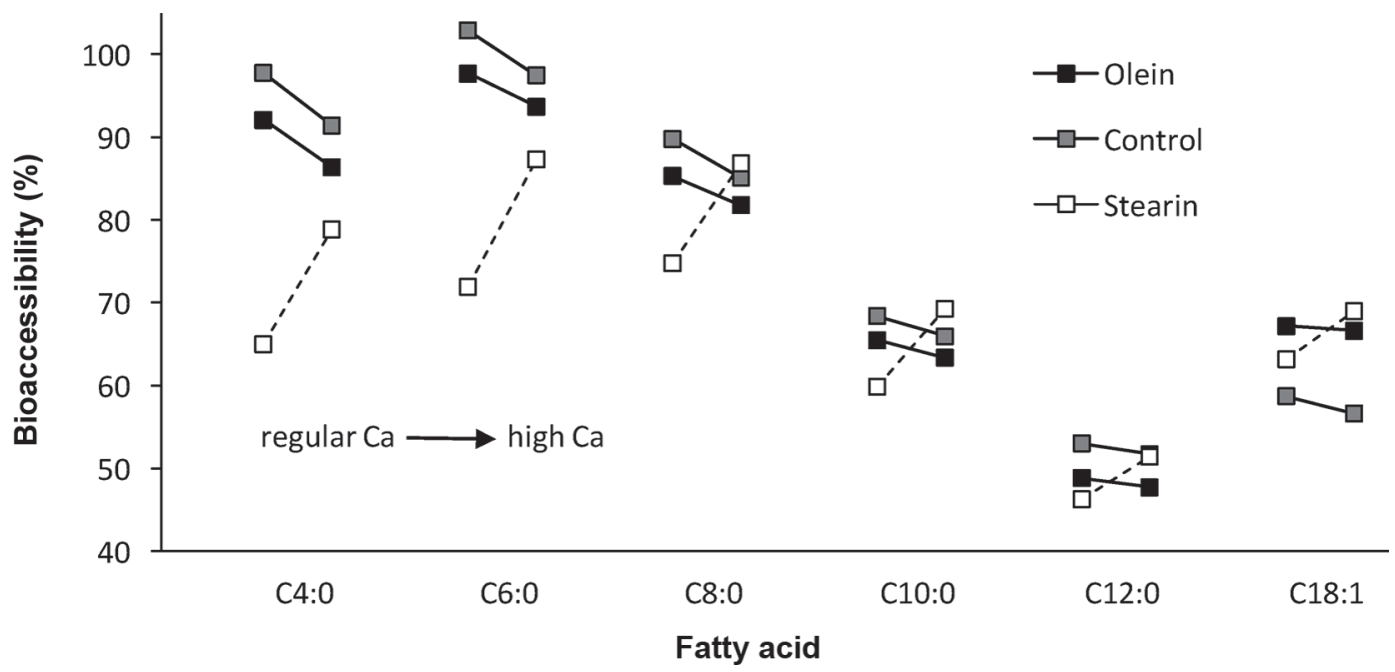

Figure 9. Bioaccessibility of short-chain, medium-chain, and unsaturated fatty acids after the in vitro digestion of Cheddar-type cheeses prepared with different Ca levels and different anhydrous milk fat types [defined as the mass fraction (\%) of fatty acids released from triacylglycerols during digestion with respect to the total amount of the corresponding fatty acid present in the respective anhydrous milk fats]. For each pair of markers, dashed connectors indicate significant differences between regular and high Ca levels (left and right markers, respectively), and solid lines indicate statistically equivalent means. SEM were 3.9, 3.0, 2.3, 1.7, 1.0, and 1.4 for C4:0, C6:0, C8:0, C10:0, C12:0, and C18:1, respectively. 
tive amount with respect to the other fatty acids. This finding appears to be in accordance with the Henderson-Hasselbalch equation \{i.e., $\mathrm{pH}=\mathrm{pK}_{a}+\log _{10}\left(\left[\mathrm{~A}^{-}\right] /\right.$ $[\mathrm{HA}])$, where $\mathrm{A}^{-}$is the conjugated base of the acid $\left.\mathrm{HA}\right\}$ for a given $\mathrm{pH}$, because the common ion among fatty acids is $\mathrm{H}^{+}$, which determines the amounts of dissociated and protonated fatty acids according to their specific dissociation constant $\left(\mathrm{K}_{a}\right)$. Protonated fatty acids would transfer into the organic phase, whereas the rest would remain soluble in the aqueous phase or as insoluble CS. It would be of interest to perform further research to better describe the partitioning of the lost fatty acids as water-soluble molecules or as CS. This information would allow us to better assess in vitro data on fatty acid solubility at $\mathrm{pH}$ close to neutrality against the physiological relevance of fatty acid solubility, as it could effect in vivo fatty acid absorption.

The extraction pairs included $2 \mathrm{pH}$ conditions for chymes obtained at the end of the in vitro digestion of each experimental cheese. Under acidic conditions $(\mathrm{pH}$ 2 ), all the lipids present in the chyme were extracted into the solvents, whereas conditions close to neutrality ( $\mathrm{pH}$ 7) would exclude water-soluble fatty acids (e.g., dissociated SCFA and MCFA) and CS, which are insoluble in both water and the solvents used. Mass losses between the extraction pairs represented around one-third of the total fat from the cheese added to the digestion tubes. No significant differences were found among the experimental cheeses, although the results do suggest a tendency toward higher mass losses when high Ca levels were present as opposed to regular Ca levels (Table 8). Consequently, the effect of Ca enrichment translated into an overall increment in CS, with $\Delta_{\mathrm{CS}}$ values suggesting higher sensitivity to Ca increase in the stearin AMF than in the other AMF types (Table 8). For the cheeses prepared with the stearin AMF, the $\Delta_{\mathrm{CS}}$ was close to the expected values considering the $\mathrm{Ca}$

Table 7. Loss ratios into the organic phase of main fatty acids after the extraction of chymes at $\mathrm{pH} 7$, in relation to the same fatty acid recovered under extraction conditions at $\mathrm{pH} 2$; when available, SEM obtained from the statistical model are reported

\begin{tabular}{lcc}
\hline Fatty acid & $\begin{array}{c}\text { Loss ratio } \\
\text { pH } 7: \mathrm{pH} 2\end{array}$ & SEM \\
\hline C4:0 & 1.000 & - \\
C6:0 & 1.000 & - \\
C8:0 & 1.000 & - \\
C10:0 & 0.912 & 0.006 \\
C14:0 & 0.794 & 0.011 \\
C15:0 & 0.584 & 0.019 \\
C16:0 & 0.444 & 0.023 \\
C18:0 & 0.292 & 0.029 \\
C18:1 1 Total fatty acids & 0.153 & 0.032 \\
\hline
\end{tabular}

increment between the 2 Ca levels used (i.e., approximately $7 \mathrm{mg}$ or $0.175 \mathrm{mmol}$, conveyed by $3 \mathrm{~g}$ of cheese in the digestion tube, potentially binding, for example, up to $89.6 \mathrm{mg}$ of palmitic acid at a 1:2 stoichiometric ratio). However, this was not the case for the $\Delta_{\mathrm{CS}}$ values for the other cheeses. Mass losses of water-soluble fatty acids were confounded with those of insoluble CS, limiting the sensitivity of the extraction technique to quantify the latter. Nevertheless, a noteworthy observation during the extractions was the presence of a white layer between the solvent supernatant and the aqueous phase, strongly suggesting the presence of CS. Although $\mathrm{CS}$ are insoluble in the solvents used, early research on the solubility of CS (Harrison, 1924) reported that they are easily dispersible in diethyl ether, which was one of the organic components. During the extractions at $\mathrm{pH}$ 7, shaking would have dispersed CS preferentially into the organic phase, which then congregated into a layer over the aqueous phase during centrifugation (Figure 10). That white layer was absent when the extractions took place at an acidic $\mathrm{pH}$, where the CS are dissociated and where protonated fatty acids solubilize into the solvent. Further tests in an ongoing study with chyme obtained after the in vitro digestion of Ca-free model dairy matrixes did not produce such a white layer, even when extraction was performed at $\mathrm{pH} 7$ (results not shown); that finding supports the idea that the layer is composed mainly of CS.

\section{CONCLUSIONS}

The in vitro digestion of Cheddar-type cheeses prepared with different AMF types and Ca levels led to different disintegration and lipolysis profiles. The most distinctive factor among the cheeses was the incorporation of a stearin AMF, with a higher proportion of solid fat at digestion temperatures. That solid fat is believed to be the main reason for the observed variations in

Table 8. Mass fractions of fat lost (ML) between extraction pairs performed at $\mathrm{pH} 2$ and 7 and increment in $\mathrm{Ca}$ soaps due to $\mathrm{Ca}$ enrichment $\left(\Delta_{\mathrm{CS}}\right)$ in chyme juices obtained after $270 \mathrm{~min}$ of in vitro digestion of Cheddar-type cheeses prepared with different anhydrous milk fat (AMF) types and with a regular Ca level (salted with $\mathrm{NaCl}$ ) or a high $\mathrm{Ca}$ level (salted with $\left.\mathrm{NaCl}+\mathrm{CaCl}_{2}\right)^{1}$

\begin{tabular}{llcc}
\hline AMF type & Ca level & ML $(\mathrm{mg} / \mathrm{g})$ & $\Delta_{\mathrm{CS}}(\mathrm{mg} / \mathrm{g})$ \\
\hline Olein & Regular & 340 & 41 \\
& High & 381 & \multirow{2}{*}{14} \\
Control & Regular & 367 & \multirow{2}{*}{94} \\
& High & 382 & \\
Stearin & Regular & 319 & - \\
SEM & High & 413 &
\end{tabular}

${ }^{1}$ The chyme samples were obtained at the end of in vitro digestion. No statistically significant differences were found. 


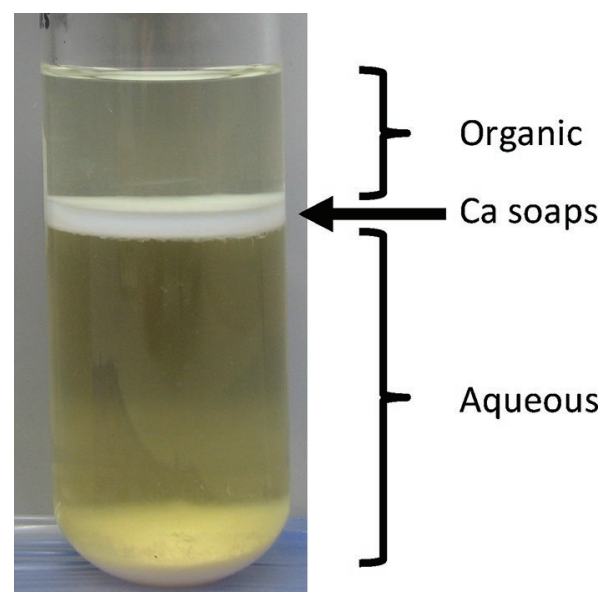

Figure 10. Typical layering of chymes during solvent extractions at $\mathrm{pH} 7$ (after centrifugation). The arrow points to the white layer of Ca soaps. The organic and aqueous phases are also indicated. Color version available online.

cheese texture and the progression of digestion, given that the cheeses with the stearin AMF were more resistant to disintegration. The Ca level, in turn, did not seem to modify cheese characteristics and did not affect cheese disintegration during digestion, but did have an effect on lipolysis during in vitro digestion. That effect was related to the depletion of LCFA from the lipid/water interface, which allowed the progression of lipolysis, which was similar toward the end of the digestions for all the cheeses, except those with the regular Ca level and the stearin AMF. During the digestion of the latter cheeses, the low lipolysis rate was due to the higher proportion of LCFA, resulting in exacerbated accumulation of lipolysis products. Calcium enrichment was found to counteract such accumulation, apparently by binding LCFA to form CS and resulting in higher SCFA, MCFA, and oleic acid release rates. Nevertheless, the bioaccessibility of fatty acids from the cheeses prepared with the stearin AMF was lower than that of the cheeses with the control or the olein AMF. This study confirms that $\mathrm{Ca}$ can play a modulating role in fatty acid bioaccessibility, and that such a role also depends on the fatty acid profile of the fat. Studies on the interaction of $\mathrm{Ca}$ with fatty acids under in vitro and in vivo digestive conditions are currently underway to provide a better understanding of the effect of $\mathrm{Ca}$ on free fatty acid bioaccessibility. In parallel, another study is underway to develop a more sensitive technique to quantify CS. In the near future, this project will enable the development of dairy matrices that, after ingestion, can modify metabolic responses and serve as effective carriers for bioactive molecules and for specifically tailored nutrition.

\section{ACKNOWLEDGMENTS}

The authors thank Gaétan Bélanger, Sophie Turcot, Martine Lussier, Sophie Lamothe, Denise Chabot, and Marie-Audrey Robert from Agriculture and Agri-Food Canada (AAFC) for their technical assistance, as well as Christelle Lopez from the Institut National de la Recherche Agronomique, Unité de Recherche en Science et Technologie du Lait et de l'Oeuf (INRA-STLO), Rennes, France, for her advice on milk fat analysis. The contribution of Fonterra Ltd. (Auckland, New Zealand) in providing the anhydrous milk fat fractions is recognized. The financial support of the Natural Sciences and Engineering Research Council of Canada (NSERC), Novalait (Québec, Canada), Ministère de l'Agriculture, des Pêcheries et de l'Alimentation du Québec (MAPAQ), and Agriculture and Agri-Food Canada (AAFC) is acknowledged.

\section{REFERENCES}

Armand, M. 2008. Milk fat digestibility. Sci. Aliments 28:84-98. Astrup, A., J.-P. Chaput, J.-A. Gilbert, and J. K. Lorenzen. 2010 Dairy beverages and energy balance. Physiol. Behav. 100:67-75.

Ayala-Bribiesca, E., M. Lussier, D. Chabot, S. L. Turgeon, and M. Britten. 2016. Effect of calcium enrichment of cheddar cheese on its structure, in vitro digestion and lipid bioaccessibility. Int. Dairy J. 53:1-9.

Barrow, M. G. 1979. Physical Chemistry. 4th ed. McGraw Hill, New York, NY.

Bauer, E., S. Jakob, and R. Mosenthin. 2005. Principles of physiology of lipid digestion. Asian-australas. J. Anim. Sci. 18:282-295.

Berry, S. E. E., G. J. Miller, and T. A. B. Sanders. 2007. The solid fat content of stearic acid-rich fats determines their postprandial effects. Am. J. Clin. Nutr. 85:1486-1494.

Björklund Jansson, M., and R. Wadsborn. 2005. Equilibrium calculations for fatty acid calcium soaps in pulp washing. STFI-Packforsk, Stockholm, Sweden.

Bonnaire, L., S. Sandra, T. Helgason, E. A. Decker, J. Weiss, and D. J. McClements. 2008. Influence of lipid physical state on the in vitro digestibility of emulsified lipids. J. Agric. Food Chem. $56: 3791-3797$.

Bourne, M. C. 1978. Texture profile analysis. Food Technol. 32:62-66., 72.

Bugaut, M. 1987. Occurrence, absorption and metabolism of short chain fatty acids in the digestive tract of mammals. Comp. Biochem. Physiol. B 86:439-472.

Carey, M. C., D. M. Small, and C. M. Bliss. 1983. Lipid digestion and absorption. Annu. Rev. Physiol. 45:651-677.

Christensen, R., J. K. Lorenzen, C. R. Svith, E. M. Bartels, E. L. Melanson, W. H. Saris, A. Tremblay, and A. Astrup. 2009. Effect of calcium from dairy and dietary supplements on faecal fat excretion: A meta-analysis of randomized controlled trials. Obes. Rev. 10:475-486.

Christie, W. W. 1995. Composition and structure of milk lipids. Pages 1-36 in Advanced Dairy Chemistry. Volume 2: Lipids. 2nd ed. P. F. Fox, ed. Chapman \& Hall, London, UK.

Collins, Y. F., P. L. H. McSweeney, and M. G. Wilkinson. 2004. Lipolysis and catabolism of fatty acids in cheese. Pages $373-389$ in Cheese: Chemistry, Physics and Microbiology. Volume 1: General Aspects. 3rd ed. P. F. Fox, P. L. H. McSweeney, T. M. Cogan, and T. P. Guinee, ed. Academic Press, London, UK.

de Jong, C., and H. T. Badings. 1990. Determination of free fatty acids in milk and cheese: Procedures for extraction, clean up, and capillary gas chromatographic analysis. J. Sep. Sci. 13:94-98. 
Deeth, H. C., and C. H. Fitz-Gerald. 1995. Lipolytic enzymes and hydrolytic rancidity in milk and milk products. Pages 247-286 in Advanced Dairy Chemistry. Volume 2: Lipids. 2nd ed. P. F. Fox, ed. Chapman \& Hall, London, UK.

deMan, J. M., and M. Finoro. 1980. Characteristics of milk fat fractionated by crystallization from the melt. Can. Inst. Food Sci Technol. J. 13:167-173.

Diem, K., and C. Lentner, eds. 1970. Geigy Scientific Tables. 7th ed. Documenta Geigy. Geigy Pharmaceuticals, Basel, Switzerland.

Favé, G., T. C. Coste, and M. Armand. 2004. Physicochemical properties of lipids: New strategies to manage fatty acid bioavailability. Cell. Mol. Biol. 50:815-831.

Garrett, P. R. 2013. The Science of Defoaming: Theory, Experiment and Applications. CRC Press, Boca Raton, FL.

Gaucheron, F. 2005. The minerals of milk. Reprod. Nutr. Dev. 45:473483.

Golding, M., and T. J. Wooster. 2010. The influence of emulsion structure and stability on lipid digestion. Curr. Opin. Colloid Interface Sci. 15:90-101.

Guéguen, L., and A. Pointillart. 2008. Digestive and metabolic interactions between lipids and calcium. Sci. Aliments 28:117-127.

Harrison, G. A. 1924. A note on the solubilities of calcium soaps. Biochem. J. 18:1222-1223.

Health Canada. 2010. The Canadian Nutrient File. 2010 ed. Health Canada, Ottawa, ON, Canada.

Hickey, D. K., K. N. Kilcawley, T. P. Beresford, and M. G. Wilkinson. 2007. Lipolysis in cheddar cheese made from raw, thermized, and pasteurized milks. J. Dairy Sci. 90:47-56.

Hu, M., Y. Li, E. A. Decker, and D. J. McClements. 2010. Role of calcium and calcium-binding agents on the lipase digestibility of emulsified lipids using an in vitro digestion model. Food Hydrocoll. 24:719-725.

Jensen, R. G., and D. S. Newburg. 1995. Bovine milk lipids. Pages 543-576 in Handbook of Milk Composition. R. G. Jensen, ed. Academic Press, San Diego, CA.

Jones, P. J. H., and S. Kubow. 2006. Lipids, sterols, and their metabolites. Pages 92-122 in Modern Nutrition in Health and Disease. 10th ed. M. E. Shils, M. Shike, A. C. Ross, B. Caballero, and R. Cousins, ed. Lippincott Williams and Wilkins, Baltimore, MD

Kaylegian, K. E., and R. C. Lindsay. 1995. Handbook of Milkfat Fractionation Technology and Application. AOCS Press, Champaign, IL.

Keenan, T. W., and S. Patton. 1995. The structure of milk: Implications for sampling and storage. A. The milk lipid globule membrane. Pages 5-50 in Handbook of Milk Composition. R. G. Jensen, ed. Academic Press, San Diego, CA.

Lamothe, S., M.-M. Corbeil, S. L. Turgeon, and M. Britten. 2012 Influence of cheese matrix on lipid digestion in a simulated gastrointestinal environment. Food Funct. 3:724-731.

Li, Y., M. Hu, and D. J. McClements. 2011. Factors affecting lipase digestibility of emulsified lipids using an in vitro digestion model: Proposal for a standardised pH-stat method. Food Chem. 126:498505

Lopez, C., C. Bourgaux, P. Lesieur, A. Riaublanc, and M. Ollivon. 2006. Milk fat and primary fractions obtained by dry fractionation: 1. Chemical composition and crystallisation properties. Chem. Phys. Lipids 144:17-33.
Lopez, C., V. Briard-Bion, C. Bourgaux, and J. Pérez. 2013. Solid triacylglycerols within human fat globules: $\beta$ crystals with a melting point above in-body temperature of infants, formed upon storage of breast milk at low temperature. Food Res. Int. 54:1541-1552.

Lucey, J. A., and P. F. Fox. 1993. Importance of calcium and phosphate in cheese manufacture: A review. J. Dairy Sci. 76:1714-1724.

Luddy, F. E., R. A. Barford, S. F. Herb, and P. Magidman. 1968. A rapid and quantitative procedure for the preparation of methyl esters of butteroil and other fats. J. Am. Oil Chem. Soc. 45:549-552.

Marten, B., M. Pfeuffer, and J. Schrezenmeir. 2006. Medium-chain triglycerides. Int. Dairy J. 16:1374-1382.

Michalski, M.-C. 2008. Impact of milk fat structure on cardiovascular risk factors. Sci. Aliments 28:150-155.

Michalski, M. C., C. Genot, C. Gayet, C. Lopez, F. Fine, F. Joffre, J. L. Vendeuvre, J. Bouvier, J. M. Chardigny, and K. Raynal-Ljutovac. 2013. Multiscale structures of lipids in foods as parameters affecting fatty acid bioavailability and lipid metabolism. Prog. Lipid Res. 52:354-373.

Minister of Justice of Canada. 2014. Dairy Products Regulations. Page 96 in SOR/79-840. Minister of Justice, Ottawa, ON, Canada.

$\mathrm{Mu}, \mathrm{H}$., and T. Porsgaard. 2005. The metabolism of structured triacylglycerols. Prog. Lipid Res. 44:430-448.

O'Mahony, J. A., P. F. Fox, and A. L. Kelly. 2013. Indigenous enzymes of milk. Pages 337-385 in Advanced Dairy Chemistry. Volume 1A Proteins: Basic Aspects. 4th ed. P. L. H. McSweeney and P. F Fox, eds. Springer Science+Business Media, New York, NY.

Ong, L., R. R. Dagastine, S. E. Kentish, and S. L. Gras. 2013. The effect of calcium chloride addition on the microstructure and composition of Cheddar cheese. Int. Dairy J. 33:135-141.

Owen, R. W., U. M. Weisgerber, J. Carr, and M. H. Harrison. 1995. Analysis of calcium-lipid complexes in faeces. Eur. J. Cancer Prev. $4: 247-255$.

Patton, J. S., and M. C. Carey. 1979. Watching fat digestion. Science 204:145-148.

Pereira, R. F. P., A. J. M. Valente, M. Fernandes, and H. D. Burrows. 2012. What drives the precipitation of long-chain calcium carboxylates (soaps) in aqueous solution? Phys. Chem. Chem. Phys. 14:7517-7527.

Philippe, M., F. Gaucheron, Y. Le Graet, F. Michel, and A. Garem. 2003. Physicochemical characterization of calcium-supplemented skim milk. Lait 83:45-59.

Robin, O., and P. Paquin. 1991. Evaluation of the particle size of fat globules in a milk model emulsion by photon correlation spectroscopy. J. Dairy Sci. 74:2440-2447.

Sassene, P., K. Kleberg, H. D. Williams, J.-C. Bakala-N'Goma, F. Carrière, M. Calderone, V. Jannin, A. Igonin, A. Partheil, D. Marchaud, E. Jule, J. Vertommen, M. Maio, R. Blundell, H. Benameur, C. J. H. Porter, C. W. Pouton, and A. Müllertz. 2014. Toward the establishment of standardized in vitro tests for lipidbased formulations, part 6: Effects of varying pancreatin and calcium levels. AAPS J. 16:1344-1357.

Versantvoort, C. H. M., A. G. Oomen, E. Van de Kamp, C. J. M. Rompelberg, and A. J. A. M. Sips. 2005. Applicability of an in vitro digestion model in assessing the bioaccessibility of mycotoxins from food. Food Chem. Toxicol. 43:31-40.

Watzke, H. J. 1998. Impact of processing on bioavailability examples of minerals in foods. Trends Food Sci. Technol. 9:320-327. 